\title{
Diferenças de gênero na República Dominicana, 1994-2004: dois passos à frente, um passo para trás?
}

\author{
Jana Morgan Kelly \\ University of Tennessee-Knoxville \\ Rosario Espinal \\ Temple University \\ Jonathan Hartlyn \\ University of North Carolina at Chapel Hill
}

\begin{abstract}
Resumo
A lenta mudança da natureza da diferença de gênero responde tanto a mudanças sociais, como urbanização, educação, o ingresso das mulheres na força de trabalho e a democratização, quanto a esforços combinados por movimentos sociais e líderes políticos para a ampliação dos direitos da mulher. Esses fatores claramente tiveram impacto na República Dominicana na última década, influenciando as diferenças de gênero no país. Avaliamos a natureza e a evolução das diferenças de gênero na Rep. Dominicana mo período de 1994 a 2004, utilizando dados de surveys nacionais - Demos surveys realizados em 1994, 1997, 2001 e 2004. A análise desses surveys indica que aspectos do que tem sido denominado uma 'diferença de gênero tradicional' permanece no país com relação ao engajamento cívico, interesse político e atitudes democráticas. Ao mesmo tempo, essa diferença desaparece com relação à participação eleitoral , e uma 'diferença moderna de gênero' emerge pela primeira vez com relação às atitudes sobre o papel da mulher na política. Idade e escolaridade têm efeitos diferenciais significativos e substantivos no conjunto de atitudes de homens e mulheres dominicanos nesse período.
\end{abstract}

Palavras-chave: diferença de gênero, participação política, democracia, Republica Dominicana

Abstract

The slowly changing nature of the gender gap responds both to significant social changes, such as urbanization, education, the entry of women into the labor force, and democratization, as well as to concerted efforts by social movements and political leaders to broaden women's right. These factors have clearly played an important role in the Dominican Republic over this past decade, impacting the country's gender gap. We assess the nature and evolution of the Dominican Republic's gender gap over the 1994-2004 period employing data taken from four nationwide public opinion surveys in the Dominican Republic - the Demos surveys - conducted in 1994, 1997, 2001, and 2004. The analysis of these surveys indicates that elements of what has been termed a traditional gender gap remain in place in the country with regard to civic engagement, political interest, and attitudes toward democracy. At the same time, this gap disappeared with regard to voter participation in elections and a modern gender gap emerged for the first time with regard to attitudes about the role of women in politics. Age and education have consistent and substantial differential effects across the attitudinal profiles of Dominican men and women over this time period.

Key words: gender gap, political participation, democracy, Dominican Republic 
Introdução

O papel das mulheres na esfera pública, seja na política ou na solução de problemas da comunidade, bem como as atitudes em relação a essa participação feminina, vem evoluindo na América Latina, alterando lentamente a natureza da diferença de gênero. Em termos amplos, acredita-se que essa evolução responda a mudanças sociais significativas, como urbanização, educação, ingresso na força de trabalho e democratização, bem como a esforços combinados de movimentos sociais e lideranças políticas para ampliar os direitos das mulheres.

Esses fatores desempenharam claramente um papel importante na República Dominicana na última década, causando impacto sobre a diferença de gênero do país. Avaliamos a natureza e a evolução dessa diferença na República Dominicana durante o período 1994-2004 em três áreas diferentes: atitudes em relação às mulheres na política, engajamento cívico e político e visões da política democrática. Em nossa análise, identificamos algumas importantes mudanças atitudinais positivas com respeito a mulheres e política, embora tenhamos concluído que elas não se sustentavam em 2004; oferecemos também provas de que os homens parecem particularmente suscetíveis a exemplos tanto positivos quanto negativos dos líderes partidários. Também confirmamos que idade e educação causam efeitos diferenciais consistentes e substanciais em todos os perfis atitudinais dos homens e mulheres dominicanos ao longo desse período de tempo. O envelhecimento tem uma forte influência positiva sobre as atitudes dos homens em relação às mulheres na política e ao interesse por política em geral, mas nenhuma influência sobre as atitudes das mulheres. Por sua vez, a educação tem um efeito positivo sobre homens e mulheres quanto às atitudes em relação à participação das mulheres na política, sendo mais substancial nas mulheres. Em contraste, descobrimos que a educação tem uma influência positiva tanto sobre homens como sobre mulheres no que diz respeito ao interesse por política, mas com um impacto substancialmente maior sobre os homens. 


\section{A diferença de gênero e a República Dominicana}

O conceito de diferença de gênero (gender gap) tem sido usado nas últimas décadas de várias maneiras para destacar as deficiências, desigualdades ou diferenças entre homens e mulheres. As primeiras pesquisas de opinião das décadas de 1950 e 1960 estabeleceram que as mulheres eram mais conservadoras do que os homens, tinham menos interesse por política e, em conseqüência, participavam menos, devido, em larga medida, a diferentes padrões de socialização (ALMOND e VERBA, 1963). Esse tipo de conservadorismo assumido das mulheres é conhecido como a "diferença de gênero tradicional" (INGLEHART e NORRIS, 2003). Porém, durante os anos 1970 e 1980, a teoria de que o conservadorismo político das mulheres era uma característica fixa e estrutural foi contestada. Novas pesquisas argumentaram que quando entravam na força de trabalho em economias mais avançadas, as mulheres desenvolviam novos interesses e começavam a votar mais à esquerda (MANZA, 1997). Em outras palavras, surgia um voto feminino mais liberal, conhecido como a "diferença de gênero moderna" (INGLEHART e NORRIS, 2003).

As mudanças nos papéis sexuais também influenciaram o modo como o conceito de diferença de gênero é utilizado. Níveis baixos de desenvolvimento econômico e educação, junto com religião, são comumente associados a "papéis tradicionais dos gêneros", baseados na subordinação das mulheres aos homens nas esferas pública e privada. Níveis mais altos de desenvolvimento econômico, mais instrução, mais participação feminina na força de trabalho e secularismo são associados a "papéis modernos dos gêneros", baseados em mais igualitarismo. Estudos empíricos comparativos levaram Inglehart e Norris (2003) a sustentar que os papéis dos gêneros estão mudando em todo o mundo, em particular nas sociedades pós-industriais, onde mudanças dramáticas em muitas questões relacionadas com o gênero ajudaram a gerar uma imensa transformação das tendências atitudinais e eleitorais, da chamada diferença de gênero tradicional para moderna. O movimento das mulheres também é identificado como um fator interveniente que ajudou a solapar a diferença tradicional e promover uma maior igualdade entre gêneros.

Neste artigo, avaliamos a natureza e a evolução da diferença de gênero da República Dominicana em três áreas diferentes: atitudes em relação às mulheres na política, engajamento cívico e político e visões da política democrática. Exploramos as atitudes e os comportamentos de mulheres e homens nessas áreas, avaliamos como se desenvolveram ao longo de um período de dez anos que foi crítico no desenvolvimento da democracia dominicana e examinamos também como as diferenças entre mulheres e homens mudaram ao longo desse período. Essa análise nos possibilita não somente estabelecer se existe uma diferença de gênero nessas 
áreas e identificar a natureza das diferenças encontradas, mas também explorar a dinâmica das diferenças de gêneros no contexto do período formativo de uma democracia emergente em que atitudes, comportamentos e instituições estão em desenvolvimento.

Além disso, o exame das atitudes em relação a mulheres, do engajamento e das percepções de democracia nos permite traçar o desenvolvimento das atitudes e comportamentos em três áreas essenciais para compreender a incorporação das mulheres à nova sociedade democrática. É provável que as atitudes dos cidadãos a respeito dos papéis das mulheres na esfera política sejam cruciais na moldagem da trajetória do seu engajamento e de sua participação na política. Se no início de uma nova democracia, homens e até mulheres acreditam que as mulheres não devem ou são incapazes de se envolver em política, então é provável que a esfera política venha a ser essencialmente um domínio dos homens. Ao contrário, se a participação das mulheres na política já é ou está se tornando cada vez mais aceita, então as perspectivas para a participação feminina na política são muito melhores. Ademais, se as mulheres se engajam civicamente, é mais provável que se envolvam na política e sua participação seja aceita, e padrões de engajamento feminino que se desenvolvem durante os anos iniciais de maior liberdade política podem contribuir para as expectativas em relação aos papéis das mulheres na política. Por fim, as atitudes em relação à democracia, tanto em teoria como na prática, oferecem informações sobre a medida em que o novo regime é percebido como bem sucedido por ambos os gêneros. As diferenças entre mulheres e homens em suas percepções da democracia podem oferecer algumas indicações de que o novo regime se desempenha melhor para um gênero do que para o outro, ou pelo menos, que um gênero tem menos entusiasmo pelo novo regime. Se as mulheres apóiam o novo regime menos do que os homens, isso pode indicar que o regime tem um viés de gênero, no sentido de que as preocupações das mulheres não são ouvidas ou não são atendidas tão bem quanto as dos homens.

A década de 1990 foi um período importante no desenvolvimento democrático do país. As primeiras seis décadas do século XX foram marcadas por instabilidade política, por uma demorada ocupação americana e pela longa e brutal ditadura de Rafael Trujillo (1930-1961), que manteve um controle rígido da população. Depois, uma figura central da era de Trujillo, Joaquín Balaguer, governou o país por 22 dos trinta anos seguintes, de 1966 a 1978, e novamente de 1986 a 1996, combinando estagnação política com uma forte transformação socioeconômica. Assim, nossa primeira pesquisa data dos anos finais do regime de Balaguer, marcados por ampla mobilização social e política em torno das eleições de 1994, e do início da atual fase de democracia política pós-Balaguer. 
Ao longo dos anos 1980 e no começo dos 1990, a República Dominicana passou também por uma enorme abertura cultural e socioeconômica para o mundo. O país mudou de uma economia baseada na exportação tradicional de produtos primários, principalmente açúcar, para uma economia centrada no turismo e na exportação de bens manufaturados leves produzidos em zonas de livre comércio. Ao mesmo tempo, o país passou a depender cada vez mais de remessas da crescente população dominicana no exterior. Na parte final da década de 1990, enquanto o resto da região ficava estagnado economicamente, a República Dominicana experimentou um crescimento econômico sustentado, que já estava começando a diminuir de ritmo no momento em que o país entrou em crise econômica, em 2003, quando ocorreram várias falências de bancos. Nesse mesmo período dos anos 1990, aprovaram-se leis que introduziam cotas de gênero nas eleições locais e postos legislativos e, em 2000, uma mulher foi eleita vice-presidenta. Assim, há várias razões para crer que as diferenças de gênero, tanto em termos de atitudes totais em relação a mulheres e política em geral, como no que diz respeito à natureza das diferenças entre homens e mulheres, deveriam ter mudado no país ao longo desse período.

\section{Explorando a diferença de gênero}

A fim de analisar a evolução da diferença de gênero durante esse período crítico da democracia dominicana, utilizamos dados de quatro pesquisas nacionais de opinião pública - os surveys Demos - realizadas em 1994, 1997, 2001 e $2004 .{ }^{1}$ As pesquisas fizeram perguntas sobre engajamento cívico e político, atitudes em relação a mulheres, percepções de democracia e uma variedade de valores sociais e políticos para os quais não havia dados disponíveis no país antes de 1994. Aqui avaliamos se existem ou não diferenças estatisticamente significativas entre mulheres e homens em suas atitudes com respeito às mulheres na política, seus engajamentos cívicos e políticos e suas percepções da democracia dominicana. Além disso, discutimos como essas atitudes e comportamentos mudaram ao longo da década analisada.

\footnotetext{
1 As pesquisas foram encomendadas pelo Projeto de Iniciativas Democráticas (PID), centrado na Pontifícia Universidade Católica Mãe e Mestra (PUCMM) e financiado pela United States Agency for International Development (USAID). Os resultados das pesquisas com tabulações e uma discussão de todas as questões foram publicados em vários livros (DUARTE et al., 1996; DUARTE et al., 1998; DUARTE e BREA, 2002). Uma discussão dos dados da pesquisa centrada no gênero para 1994 e 1997 encontra-se em Duarte e Brea (1999).
} 
Tabela 1

Opiniões sobre a participação política das mulheres por gêneroa

\begin{tabular}{|c|c|c|c|c|}
\hline Variável & Ano & Masculino & Feminino & Amostra total \\
\hline \multirow{4}{*}{$\begin{array}{l}\text { Política é para os } \\
\text { homens }\end{array}$} & 1994 & $\begin{array}{c}0,49 \\
(0,02)\end{array}$ & $\begin{array}{c}0,51 \\
(0,02)\end{array}$ & $\begin{array}{c}0,50 \\
(0,02)\end{array}$ \\
\hline & 1997 & $\begin{array}{c}0,35 \\
(0,02) \\
\end{array}$ & $\begin{array}{c}0,33 \\
(0,02) \\
\end{array}$ & $\begin{array}{c}0,34 \\
(0,01) \\
\end{array}$ \\
\hline & 2001 & $\begin{array}{c}0,28 \\
(0,01)\end{array}$ & $\begin{array}{c}0,28 \\
(0,01)\end{array}$ & $\begin{array}{c}0,28 \\
(0,01)\end{array}$ \\
\hline & 2004 & $\begin{array}{l}0,44^{\star} \\
(0,02)\end{array}$ & $\begin{array}{l}0,40^{\star} \\
(0,02)\end{array}$ & $\begin{array}{c}0,42 \\
(0,01)\end{array}$ \\
\hline \multirow{4}{*}{$\begin{array}{l}\text { Mais participação } \\
\text { política das mulheres }\end{array}$} & 1994 & $\begin{array}{c}0,74 \\
(0,02)\end{array}$ & $\begin{array}{c}0,74 \\
(0,02)\end{array}$ & $\begin{array}{c}0,74 \\
(0,01)\end{array}$ \\
\hline & 1997 & $\begin{array}{c}0,85 \\
(0,01)\end{array}$ & $\begin{array}{c}0,88 \\
(0,01)\end{array}$ & $\begin{array}{c}0,87 \\
(0,01)\end{array}$ \\
\hline & 2001 & $\begin{array}{l}0,87^{\star} \\
(0,01)\end{array}$ & $\begin{array}{l}0,89 \star \\
(0,01)\end{array}$ & $\begin{array}{c}0,88 \\
(0,01)\end{array}$ \\
\hline & 2004 & $\begin{array}{c}0,76^{* *} \\
(0,01)\end{array}$ & $\begin{array}{c}0,82^{\star *} \\
(0,01)\end{array}$ & $\begin{array}{c}0,79 \\
(0,01)\end{array}$ \\
\hline \multirow{4}{*}{$\begin{array}{l}\text { As mulheres } \\
\text { deveriam participar } \\
\text { da política tanto } \\
\text { quanto os homens }\end{array}$} & 1994 & $\begin{array}{c}0,53 \\
(0,02)\end{array}$ & $\begin{array}{c}0,50 \\
(0,02)\end{array}$ & $\begin{array}{c}0,51 \\
(0,02)\end{array}$ \\
\hline & 1997 & $\begin{array}{c}0,64 \\
(0,01)\end{array}$ & $\begin{array}{c}0,61 \\
(0,01)\end{array}$ & $\begin{array}{c}0,62 \\
(0,01)\end{array}$ \\
\hline & 2001 & $\begin{array}{c}0,70 \\
(0,01)\end{array}$ & $\begin{array}{c}0,71 \\
(0,01) \\
\end{array}$ & $\begin{array}{c}0,71 \\
(0,01)\end{array}$ \\
\hline & 2004 & $\begin{array}{l}0,69 * * \\
(0,01)\end{array}$ & $\begin{array}{l}0,77^{\star *} \\
(0,01)\end{array}$ & $\begin{array}{c}0,73 \\
(0,01)\end{array}$ \\
\hline \multirow{4}{*}{$\begin{array}{l}\text { As mulheres } \\
\text { candidatas inspiram } \\
\text { pelo menos tanta } \\
\text { confiança quanto os } \\
\text { homens }\end{array}$} & 1994 & $\begin{array}{l}0,35 * * \\
(0,01)\end{array}$ & $\begin{array}{l}0,46 * * \\
(0,02)\end{array}$ & $\begin{array}{c}0,40 \\
(0,01)\end{array}$ \\
\hline & 1997 & $\begin{array}{c}0,54 \\
(0,01)\end{array}$ & $\begin{array}{c}0,58 \\
(0,02)\end{array}$ & $\begin{array}{c}0,57 \\
(0,01)\end{array}$ \\
\hline & 2001 & $\begin{array}{l}0,63^{* *} \\
(0,02) \\
\end{array}$ & $\begin{array}{l}0,71 * * \\
(0,01) \\
\end{array}$ & $\begin{array}{c}0,67 \\
(0,01)\end{array}$ \\
\hline & 2004 & $\begin{array}{l}0,53 * * \\
(0,02)\end{array}$ & $\begin{array}{l}0,62^{* *} \\
(0,01)\end{array}$ & $\begin{array}{c}0,58 \\
(0,01)\end{array}$ \\
\hline
\end{tabular}


KELLY, J.M.; ESPINAL, R.; HARTLYN, J. Diferenças de gênero na República Dominicana....

\begin{tabular}{|c|c|c|c|c|}
\hline Variável & Ano & Masculino & Feminino & Amostra total \\
\hline \multirow{4}{*}{$\begin{array}{l}\text { As mulheres têm } \\
\text { pelo menos tanta } \\
\text { capacidade de } \\
\text { governar quanto os } \\
\text { homens }\end{array}$} & 1994 & $\begin{array}{c}0,45 * * \\
(0,02)\end{array}$ & $\begin{array}{c}0,52^{\star *} \\
(0,02)\end{array}$ & $\begin{array}{c}0,49 \\
(0,02)\end{array}$ \\
\hline & 1997 & $\begin{array}{c}0,56 \\
(0,02) \\
\end{array}$ & $\begin{array}{c}0,59 \\
(0,02) \\
\end{array}$ & $\begin{array}{c}0,57 \\
(0,01) \\
\end{array}$ \\
\hline & 2001 & $\begin{array}{c}0,60 * * \\
(0,02)\end{array}$ & $\begin{array}{c}0,68 * * \\
(0,02)\end{array}$ & $\begin{array}{c}0,64 \\
(0,01)\end{array}$ \\
\hline & 2004 & $\begin{array}{c}0,56^{* *} \\
(0,02)\end{array}$ & $\begin{array}{c}0,67^{\star *} \\
(0,02)\end{array}$ & $\begin{array}{c}0,62 \\
(0,01)\end{array}$ \\
\hline \multirow{4}{*}{$\begin{array}{l}\text { Escala de atitudes } \\
\text { em relação às } \\
\text { mulheres na política }\end{array}$} & 1994 & $\begin{array}{c}2,59 \\
(0,07)\end{array}$ & $\begin{array}{c}2,73 \\
(0,08)\end{array}$ & $\begin{array}{c}2,66 \\
(0,06)\end{array}$ \\
\hline & 1997 & $\begin{array}{c}3,26 \\
(0,05)\end{array}$ & $\begin{array}{c}3,32 \\
(0,06)\end{array}$ & $\begin{array}{c}3,29 \\
(0,05)\end{array}$ \\
\hline & 2001 & $\begin{array}{c}3,54^{\star \star} \\
(0,05)\end{array}$ & $\begin{array}{c}3,74 * * \\
(0,05)\end{array}$ & $\begin{array}{c}3,64 \\
(0,04)\end{array}$ \\
\hline & 2004 & $\begin{array}{c}3,09 * * \\
(0,06)\end{array}$ & $\begin{array}{c}3,51 * * \\
(0,05)\end{array}$ & $\begin{array}{c}3,31 \\
(0,04)\end{array}$ \\
\hline \multicolumn{5}{|c|}{$\begin{array}{l}\text { a As médias são ponderadas para corrigir efeitos de amostragem; as diferenças de resultados não ponderados } \\
\text { são mínimas. } \\
\text { Nota: Erros padrão estão entre parênteses. * } p \leq 0,05 ; * * p \leq 0,01 \text { indica que média para homens é } \\
\text { significativamente diferente da média para mulheres usando testes t bilaterais. Testes de significância são } \\
\text { bilaterais. }\end{array}$} \\
\hline
\end{tabular}

Usando a Tabela 1, podemos avaliar a existência e a natureza de uma diferença de gênero nas visões do envolvimento das mulheres na política e traçar a evolução dessas atitudes ao longo do tempo. A Tabela apresenta as respostas de homens e mulheres a cinco itens de pesquisa separados que captam as atitudes dos respondentes em relação ao envolvimento das mulheres em diferentes aspectos da política, bem como escores em uma escala aditiva que combina esses itens. ${ }^{2}$ Começando com uma avaliação de uma diferença de gênero, observamos que há provas limitadas da existência de tal diferença, tradicional ou moderna, em atitudes com relação a mulheres na política em 1994 e 1997. Somente em 1994 vemos alguma diferença significativa entre homens e mulheres, com os homens mostrando significativamente menos apoio às mulheres candidatas e às mulheres no governo, o que representa o grau mais alto de engajamento na política - concorrer e ocupar um cargo eletivo. Porém, em 2001, uma diferença de gênero moderna começa a surgir de um modo mais geral, à medida que visões positivas da participação política feminina

\footnotetext{
${ }^{2}$ A escala vai de zero a cinco, com valores de alfa de Cronbach em torno de 0,70 em todas as quatro pesquisas indicando que a escala é confiável. Os respondentes pontuam um ponto cada por concordar que as candidatas do sexo feminino inspiram tanta ou mais confiança do que os do sexo masculino, e que as mulheres têm tanta ou mais capacidade para governar quanto os homens, e por discordar da declaração que "política é para homens".
} 
aumentam entre as mulheres mais rapidamente do que entre os homens. Em 2004, as mulheres já apóiam significativamente mais (do que os homens) seu envolvimento na política, tanto de um modo geral como específico. Em todos os cinco itens separados e na escala aditiva, as mulheres são claramente mais igualitárias em suas opiniões sobre a participação e a capacidade políticas.

Tanto entre os homens como entre as mulheres, observamos um aumento do igualitarismo em relação à aceitação da participação das mulheres na política entre 1994 e 2004. Uma proporção crescente de respondentes, de ambos os sexos, rejeitou a idéia de que a política deveria ser reservada para os homens, apoiou a participação das mulheres na política, expressou confiança nas candidatas mulheres e julgou que elas tinham tanta capacidade de governar quanto os homens. Refletindo esse padrão, a escala de atitudes em relação às mulheres na política também mostra um padrão geral de movimento na direção do igualitarismo ao longo da década.

Porém, dentro desse padrão geral, devemos fazer uma qualificação importante quanto à linha tendencial em 2004. Embora haja um grau crescente de igualitarismo de 1994 a 2001 em todos os seis itens da Tabela, em 2004 observamos um leve declínio na proporção de respondentes que não concordam que a política é coisa para os homens, que acham que as mulheres deveriam participar mais da política e que pensam que as mulheres são boas candidatas ou governantes. Desse modo, ainda que sejam evidentes os avanços consideráveis do igualitarismo nos primeiros sete anos do período, nos últimos três anos, observamos alguma regressão a níveis que foram alcançados pela primeira vez em 1997. Esse declínio da visão igualitária da participação política das mulheres na pesquisa de 2004 é particularmente claro entre os respondentes do sexo masculino, enquanto que as mulheres parecem ter mantido opiniões mais firmes. A reversão do apoio às mulheres na política muito maior entre os homens contribui para a significância consistente da diferença de gênero na pesquisa de 2004. A razão para esse declínio pode se dever ao fato de que a primeira vice-presidenta participou de um governo altamente desacreditado, combinada com as insinuações machistas da campanha presidencial em andamento quando a pesquisa foi realizada, no início de 2004.

O desenvolvimento global das atitudes em relação às mulheres na política aponta para um progresso na direção do igualitarismo. Mostramos que no início do atual período democrático, nem homens, nem mulheres tinham opiniões favoráveis sobre o envolvimento das mulheres na esfera política, mas à medida que o tempo passou, as visões igualitárias sobre a participação aumentaram em geral entre as mulheres e, em menor medida, entre os homens. Porém, uma reversão recente nas atitudes em relação a essas questões indica que os avanços nessa área não foram bem solidificados e que os homens, em particular, podem retirar o apoio à participação das mulheres. 
KELLY, J.M.; ESPINAL, R.; HARTLYN, J. Diferenças de gênero na República Dominicana....

Ao avaliar diferenças de gênero, é importante ir além da análise de atitudes com respeito ao envolvimento das mulheres na esfera política e examinar se existem ou não diferenças tangíveis de comportamento entre homens e mulheres. É importante também explorar mudanças nesses comportamentos examinando as taxas reais de participação numa variedade de atividades cívicas e políticas. A Tabela 2 mostra o engajamento cívico e político na República Dominicana durante o período de dez anos sob análise. Temos condições de examinar a presença ou ausência de uma diferença de gênero em engajamento cívico, interesse político e voto.

Tabela 2

Engajamento cívico e político por gênero ${ }^{a}$

\begin{tabular}{|c|c|c|c|c|}
\hline Nome da variável & Ano & Masculino & Feminino & Amostra total \\
\hline \multirow{4}{*}{ Engajamento cívico } & 1994 & $\begin{array}{c}2,30 * * \\
(0,06)\end{array}$ & $\begin{array}{c}1,71 * * \\
(0,07)\end{array}$ & $\begin{array}{c}2,00 \\
(0,05)\end{array}$ \\
\hline & 1997 & $\begin{array}{l}1,67 * \star \\
(0,05)\end{array}$ & $\begin{array}{c}1,00 * * \\
(0,04)\end{array}$ & $\begin{array}{c}1,28 \\
(0,04)\end{array}$ \\
\hline & 2001 & $\begin{array}{c}1,46 * \star \\
(0,05)\end{array}$ & $\begin{array}{c}1,02 * \star \\
(0,04)\end{array}$ & $\begin{array}{c}1,24 \\
(0,04)\end{array}$ \\
\hline & 2004 & $\begin{array}{c}1,26 * \star \\
(0,01)\end{array}$ & $\begin{array}{l}, 94 * \star \\
(0,04)\end{array}$ & $\begin{array}{c}1,09 \\
(0,04)\end{array}$ \\
\hline \multirow{4}{*}{ Interesse por política } & 1994 & $\begin{array}{l}2,92 * \star \\
(0,05)\end{array}$ & $\begin{array}{c}1,96 * \star \\
(0,05)\end{array}$ & $\begin{array}{c}2,43 \\
(0,06)\end{array}$ \\
\hline & 1997 & $\begin{array}{c}3,09 * * \\
(0,07)\end{array}$ & $\begin{array}{c}2,08 * \star \\
(0,05)\end{array}$ & $\begin{array}{c}2,50 \\
(0,05)\end{array}$ \\
\hline & 2001 & $\begin{array}{c}2,90 * \star \\
(0,05)\end{array}$ & $\begin{array}{c}2,14 * \star \\
(0,05)\end{array}$ & $\begin{array}{c}2,52 * \star \\
(0,04)\end{array}$ \\
\hline & 2004 & $\begin{array}{c}2,86 * \star \\
(0,05)\end{array}$ & $\begin{array}{c}2,31 * \star \\
(0,05)\end{array}$ & $\begin{array}{c}2,57 * \star \\
(0,04)\end{array}$ \\
\hline \multirow{4}{*}{$\begin{array}{l}\text { Voto: vai votar nas } \\
\text { próximas eleições }\end{array}$} & $\begin{array}{c}1994 \\
\text { (Presidencial) }\end{array}$ & $\begin{array}{c}0,91 * * \\
(0,01)\end{array}$ & $\begin{array}{c}0,85 * * \\
(0,01)\end{array}$ & $\begin{array}{c}0,88 \\
(0,01)\end{array}$ \\
\hline & $\begin{array}{c}1997 \\
\text { (Legislativa) }\end{array}$ & $\begin{array}{l}0,77 * \\
(0,01)\end{array}$ & $\begin{array}{l}0,73^{\star} \\
(0,02)\end{array}$ & $\begin{array}{c}0,75 \\
(0,01)\end{array}$ \\
\hline & $\begin{array}{c}2001 \\
\text { (Legislativa) }\end{array}$ & $\begin{array}{c}0,68 * * \\
(0,02)\end{array}$ & $\begin{array}{c}0,61 * * \\
(0,02)\end{array}$ & $\begin{array}{c}0,65 \\
(0,01)\end{array}$ \\
\hline & $\begin{array}{c}2004 \\
\text { (Presidencial) }\end{array}$ & $\begin{array}{c}0,74 \\
(0,01)\end{array}$ & $\begin{array}{c}0,71 \\
(0,01)\end{array}$ & $\begin{array}{c}0,72 \\
(0,01)\end{array}$ \\
\hline \multicolumn{5}{|c|}{$\begin{array}{c}\text { a Médias registradas são ponderadas para corrigir efeitos de amostragem do survey; as diferenças entre resultad } \\
\text { ponderados e não ponderados são mínimas. } \\
\text { Nota: Erros padrão estão entre parênteses. * } p \leq 0,05 ; * * p \leq 0,01 \text { indica que média para homens é } \\
\text { significativamente diferente da média para mulheres usando testes t bilaterais. Testes de significância são } \\
\text { bilaterais. }\end{array}$} \\
\hline
\end{tabular}


A escala de engajamento cívico, que vai de zero a dez, mede a participação dos respondentes em reuniões de bairro, bem como a participação em oito tipos diferentes de organizações que vão de associações de pais a associações camponesas e grupos esportivos. Como vemos na Tabela 2, os homens participavam desses grupos e organizações de forma mas significativa do que as mulheres em todas as quatro pesquisas. Embora o tamanho da distância diminua um pouco entre 1994 e 2004, a presença e a significância de uma diferença tradicional de gênero nesse tipo de engajamento na sociedade persiste ao longo de todo o período. Em geral, o engajamento cívico de homens e mulheres diminuiu perto de $50 \%$ em dez anos. Esse dado indica que depois do surto de participação cívica e mobilização política em torno do processo eleitoral de 1994, talvez tenha vindo o esvaziamento e desencanto e o surgimento de outras formas mais tradicionais de expressão e participação, ${ }^{3}$ significando que o envolvimento em organizações da sociedade civil tornou-se menos significativo, passando por um declínio monotônico.

Embora a participação dos dominicanos na sociedade civil tenha diminuído desde a transição para a democracia, seu interesse pela política e seu engajamento, na verdade, aumentaram. O interesse pela política é medido como uma escala aditiva que inclui o interesse geral pela política, a atenção às notícias políticas e participação em discussões políticas, e varia de 0 a 6 . Na Tabela 2, podemos ver que o nível total de interesse político aumentou levemente entre 1994 e 2004. 0 grau de interesse dos homens permaneceu mais ou menos constante, com um leve declínio ao longo da década, mas o das respondentes do sexo feminino aumentou consideravelmente de 1,96, em 1994, para 2,31, dez anos depois. Assim, embora persista uma diferença tradicional de gênero em interesse político na República Dominicana, ocorreram avanços notáveis na diminuição dessa distância. Na verdade, se a tendência atual continuar, é provável que mulheres e homens alcancem níveis iguais de interesse pela política dentro dos próximos dez anos.

Um passo adiante do interesse ativo pela política está a participação efetiva no processo político democrático, que avaliamos usando itens da pesquisa que perguntam sobre participação futura nas eleições. Especificamente, pergunta-se se os respondentes pretendem ou não votar nas próximas eleições. ${ }^{4}$ Podemos observar a diminuição da diferença de gênero na intenção dos respondentes de votar. $\mathrm{Na}$

\footnotetext{
3 Houve uma prolongada crise pós-eleitoral em 1994, quando os partidos de oposição e observadores internacionais concluíram que as fraudes no dia da eleição alteraram o resultado, dando a Balaguer uma vitória por pequena margem; após negociações complexas, Balaguer concordou com uma série de medidas constitucionais, entre elas a diminuição de seu mandato presidencial de quatro para dois anos e uma proibição de reeleição presidencial imediata.

4 Perguntou-se também aos respondentes sobre sua participação em eleições anteriores e as tendências nos dos sexos foram similares àquelas registradas no texto relativo à participação em eleições futuras.
} 
pesquisa de 1994, uma proporção significativamente maior de homens do que de mulheres indicou que planejava votar na próxima eleição presidencial, mas em 2004, não observamos nenhuma diferença significativa entre os gêneros na intenção de votar na eleição presidencial daquele ano. Porém, o padrão total da inclinação dos respondentes a participar politicamente através do voto é, na verdade, de declínio entre as eleições presidenciais de 1994 e 2004 (e é particularmente evidente na pesquisa de 2001 no que diz respeito à intenção de votar nas eleições legislativas e locais seguintes, marcadas para maio de 2002). Parece que o item "intenção de votar" capta mais a probabilidade atual de participação eleitoral dos respondentes. Isso se espera particularmente nas pesquisas de 1994 e 2004, quando as eleições a que o item se refere estavam distantes apenas dois ou três meses.

Tomados em conjunto, os resultados sobre atitudes em relação às mulheres na política e sobre engajamento cívico e político indicam que as mulheres dominicanas fizeram progressos importantes no sentido de obter um clima político igualitário desde o retorno do país à democracia. As atitudes quanto à participação das mulheres na política melhoraram consideravelmente entre 1994 e 2004, apesar do pequeno recuo entre 2001 e 2004 . No conjunto, homens e mulheres aceitaram cada vez mais essa participação em geral, ou no nível da participação de base, bem como apoiaram as mulheres nos papéis de candidatas e até de governantes. Em especial, é notável que as próprias mulheres tenham se tornado muito mais abertas à idéia de que podem e, na verdade, devem participar da política. Em 2001 e 2004, observamos a emergência de uma diferença de gênero nas atitudes em relação às mulheres na política, com as mulheres sendo significativamente mais abertas nessas questões do que os homens. Nas áreas de engajamento político ativo e participação, as mulheres também fizeram alguns progressos. Não observamos avanços notáveis, mas entre 1994 e 2004, encontramos alguma diminuição da diferença de gênero tradicional. Essa diminuição é mais evidente no voto, onde vemos uma completa eliminação das diferenças entre mulheres e homens em sua participação nas eleições presidenciais. Ademais, as diferenças tradicionais em engajamento cívico e interesse político reduziram-se em cerca de 50\% durante a década.

Esses resultados nos dizem que o clima a favor da participação das mulheres e a própria participação na política democrática na República Dominicana aumentaram nos últimos dez anos. O que resta a ser examinado é se há diferenças de gênero em como se avalia esse novo regime democrático. Se as mulheres acham que seus interesses não são ouvidos ou atendidos - em outras palavras, se a nova democracia não parece funcionar para elas - então elas podem fazer avaliações mais negativas do regime. Na Tabela 3, apresentamos as posições dos respondentes em vários itens diferentes que propiciam avaliações da democracia na 
República Dominicana. As duas primeiras variáveis dizem respeito ao funcionamento da democracia e as duas últimas avaliam o grau de compromisso dos respondentes com a democracia. Em geral, ao longo da década, podemos ver que as avaliações da democracia feitas pelos respondentes se tornaram cada vez mais negativas, com menos respondentes dizendo que ela funciona e que thes proporciona alguns benefícios. Porém, o apoio mais amplo à democracia como tipo de regime continua constante. Em particular, cerca de três quartos dos respondentes preferem a democracia a qualquer outra forma de governo, embora apenas cerca de $30 \%$ indiquem que prefeririam mais democracia, ainda que isso significasse um pouco de desordem.

Tabela 3

Avaliação de governo e democracia por gênero ${ }^{a}$

\begin{tabular}{|c|c|c|c|c|}
\hline Nome da variável & Ano & Masculino & Feminino & Amostra total \\
\hline \multirow{4}{*}{$\begin{array}{l}\text { Avaliação dos serviços } \\
\text { públicos (de } 0 \text {, toda } \\
\text { negativa, a } 7, \text { toda } \\
\text { positiva) }\end{array}$} & 1994 & $\begin{array}{c}2,31 \\
(0,09)\end{array}$ & $\begin{array}{c}2,48 \\
(0,11)\end{array}$ & $\begin{array}{c}2,39 \\
(0,08)\end{array}$ \\
\hline & 1997 & $\begin{array}{l}2,18^{*} \\
(0,09)\end{array}$ & $\begin{array}{l}1,92^{\star} \\
(0,10)\end{array}$ & $\begin{array}{c}2,05 \\
(0,08)\end{array}$ \\
\hline & 2001 & $\begin{array}{c}2,51 \\
(0,08)\end{array}$ & $\begin{array}{c}2,53 \\
(0,08) \\
\end{array}$ & $\begin{array}{c}2,52 \\
(0,07) \\
\end{array}$ \\
\hline & 2004 & $\begin{array}{c}1,74 \\
(0,08)\end{array}$ & $\begin{array}{c}1,62 \\
(0,06)\end{array}$ & $\begin{array}{c}1,68 \\
(0,05)\end{array}$ \\
\hline \multirow{4}{*}{$\begin{array}{l}\text { A democracia funciona } \\
\text { (de } 1, \text { muito mal, a } 5, \\
\text { muito bem) }\end{array}$} & 1994 & $\begin{array}{c}2,93^{* *} \\
(0,04)\end{array}$ & $\begin{array}{c}2,78^{* *} \\
(0,03)\end{array}$ & $\begin{array}{c}2,82 \\
(0,03)\end{array}$ \\
\hline & 1997 & $\begin{array}{c}3,00 * * \\
(0,03)\end{array}$ & $\begin{array}{l}2,76^{* *} \\
(0,03)\end{array}$ & $\begin{array}{c}2,86 \\
(0,03)\end{array}$ \\
\hline & 2001 & $\begin{array}{c}2,77^{* *} \\
(0,03)\end{array}$ & $\begin{array}{c}2,54 * * \\
(0,03)\end{array}$ & $\begin{array}{c}2,65 \\
(0,03)\end{array}$ \\
\hline & 2004 & $\begin{array}{l}2,37 * * \\
(0,04)\end{array}$ & $\begin{array}{c}2,15^{\star *} \\
(0,02)\end{array}$ & $\begin{array}{c}2,25 \\
(0,02)\end{array}$ \\
\hline \multirow{4}{*}{$\begin{array}{l}\text { A democracia me } \\
\text { beneficia (de 1, me } \\
\text { prejudica, a } 4, \text { muito) }\end{array}$} & 1994 & $\begin{array}{c}2,45^{* *} \\
(0,03)\end{array}$ & $\begin{array}{c}2,28^{* *} \\
(0,03)\end{array}$ & $\begin{array}{c}2,37 \\
(0,02)\end{array}$ \\
\hline & 1997 & $\begin{array}{l}2,48 * * \\
(0,03)\end{array}$ & $\begin{array}{c}2,24 * * \\
(0,03)\end{array}$ & $\begin{array}{c}2,34 \\
(0,02)\end{array}$ \\
\hline & 2001 & $\begin{array}{c}2,26 * * \\
(0,03)\end{array}$ & $\begin{array}{c}2,09 * * \\
(0,03)\end{array}$ & $\begin{array}{c}2,18 \\
(0,02)\end{array}$ \\
\hline & 2004 & $\begin{array}{c}1,86 \\
(0,04)\end{array}$ & $\begin{array}{c}1,78 \\
(0,03)\end{array}$ & $\begin{array}{c}1,81 \\
(0,02)\end{array}$ \\
\hline
\end{tabular}


KELLY, J.M.; ESPINAL, R.; HARTLYN, J. Diferenças de gênero na República Dominicana....

\begin{tabular}{|c|c|c|c|c|}
\hline Nome da variável & Ano & Masculino & Feminino & Amostra total \\
\hline \multirow{4}{*}{$\begin{array}{l}\text { Democracia acima de } \\
\text { qualquer outro tipo de } \\
\text { governo (porcentagem } \\
\text { que concorda) }\end{array}$} & 1994 & NA & NA & NA \\
\hline & 1997 & $\begin{array}{l}80 * * \\
(0,01)\end{array}$ & $\begin{array}{l}73 * * \\
(0,01)\end{array}$ & $\begin{array}{c}76 \\
(0,01)\end{array}$ \\
\hline & 2001 & $\begin{array}{l}83 * * \\
(0,01)\end{array}$ & $\begin{array}{l}75^{* *} \\
(0,01)\end{array}$ & $\begin{array}{c}79 \\
(0,01)\end{array}$ \\
\hline & 2004 & $\begin{array}{c}74 \\
(0,02) \\
\end{array}$ & $\begin{array}{c}74 \\
(0,02) \\
\end{array}$ & $\begin{array}{c}74 \\
(0,01) \\
\end{array}$ \\
\hline \multirow{4}{*}{$\begin{array}{l}\text { Democracia acima da } \\
\text { ordem (porcentagem } \\
\text { que concorda) }\end{array}$} & 1994 & $\begin{array}{l}35 * * \\
(0,02)\end{array}$ & $\begin{array}{l}26 * * \\
(0,02)\end{array}$ & $\begin{array}{c}30 \\
(0,01)\end{array}$ \\
\hline & 1997 & $\begin{array}{c}41^{* *} \\
(0,02)\end{array}$ & $\begin{array}{l}27 * \star \\
(0,01)\end{array}$ & $\begin{array}{c}33 \\
(0,01)\end{array}$ \\
\hline & 2001 & $\begin{array}{l}42^{\star *} \\
(0,02)\end{array}$ & $\begin{array}{l}31 * * \\
(0,01)\end{array}$ & $\begin{array}{c}36 \\
(0,01)\end{array}$ \\
\hline & 2004 & $\begin{array}{c}34^{*} \\
(0,02) \\
\end{array}$ & $\begin{array}{c}29 * \\
(0,01)\end{array}$ & $\begin{array}{c}31 \\
(0,01) \\
\end{array}$ \\
\hline \multicolumn{5}{|c|}{$\begin{array}{l}\text { a Médias registradas são ponderadas para corrigir efeitos de amostragem do survey; as diferenças entre resultado } \\
\text { ponderados e não ponderados são mínimas. } \\
\text { Nota: Erros padrão estão entre parênteses. }{ }^{*} p \leq 0,05 ;{ }^{* *} p \leq 0,01 \text { indica que média para homens é } \\
\text { significativamente diferente da média para mulheres usando testes t bilaterais. Testes de significância são } \\
\text { bilaterais. }\end{array}$} \\
\hline
\end{tabular}

Em 1994, 1997 e 2001, há uma clara diferença de gênero tanto nas avaliações do regime democrático como no compromisso com o tipo de regime. A única exceção ocorre diante do pedido para avaliar ações específicas do governo, tais como provisão de serviços, quando não se observam diferenças de gênero significativas. O único ano em que se discernem distinções significantes entre homens e mulheres é 1997, quando as mulheres apresentaram opiniões levemente mais positivas do que os homens sobre a provisão de serviços pelo governo. Mas no conjunto, as avaliações dos serviços públicos são similares em ambos os sexos e observamos um padrão de declínio das avaliações entre 1994 e 2004. Mas nas quatro perguntas que estão mais voltadas para as percepções do regime, em vez de do governo, em média, os homens têm uma opinião mais positiva da democracia do que as mulheres. Mais homens acharam que a democracia funciona, que é benéfica para eles, que é o melhor tipo de regime e que a democracia vale um pouco de desordem. Porém, em 2004, as diferenças de gênero desapareceram em dois dos quatro itens. Homens e mulheres tinham opiniões semelhantes quanto aos benefícios da democracia e também quanto à preferência da democracia a outros tipos de regime. O regime democrático é avaliado cada vez mais da mesma forma 
por ambos os gêneros, o que oferece algum indício de que as mulheres não consideram a democracia menos benéfica para elas do que os homens. Infelizmente, essa diminuição da diferença de gênero nesses itens não é resultado da melhoria das avaliações femininas da democracia, mas da deterioração da avaliação masculina. O novo regime democrático não melhorou sua posição aos olhos das mulheres por tratar melhor e de forma mais igual suas preocupações, mas perdeu terreno entre os homens, que sentem cada vez mais que a democracia não está realmente funcionando e os beneficiando. Portanto, embora tenhamos visto passos positivos na abertura de mentes e portas para o envolvimento político das mulheres, até agora isso não se traduziu em mais apoio para o regime democrático. Considerando o declínio na intenção declarada de votar ao lado da eliminação da diferença de gênero vista na Tabela 2 e os resultados relativos à avaliação da democracia na Tabela 3, parece que o que foi ganho por uma mudança de atitude em relação à maior participação das mulheres na política (Tabela 1) talvez tenha sido parcialmente perdido com o aumento do descontentamento com a democracia. ${ }^{5}$

\section{Explicando as atitudes em relação às mulheres na política}

Além de analisar a natureza e a evolução de uma diferença de gênero nessas questões amplas, buscamos também explicar os fatores causais que moldaram as atitudes em relação às mulheres na política e o engajamento político das mulheres em comparação com os dos homens durante o processo de democratização. Especificamente, examinamos nossas variáveis dependentes de atitudes em relação à participação das mulheres na política, usando a escala aditiva desenvolvida acima, bem como o engajamento na política, medido com o uso da escala de interesse pela política.

Começamos analisando as atitudes em relação à participação feminina na política. Nessa análise, consideramos três conjuntos importantes de hipóteses que podem explicar as opiniões dos respondentes sobre o envolvimento político das mulheres. Primeiro, esperamos que o modo como as pessoas vêem os papéis das mulheres na sociedade mais ampla provavelmente molde suas percepções positivas ou negativas da aceitação ou desejabilidade do envolvimento político das mulheres. Com freqüência, a política é considerada uma esfera complicada e competitiva que deveria ser reservada para os homens. Porém, é provável que as pessoas que têm

\footnotetext{
5 Nossas análises multivariadas preliminares com o apoio à democracia como variável dependente não geraram modelos causais efetivos e não estão incluídas aqui.
} 
uma visão mais igualitária em geral estejam mais abertas à possibilidade da igual participação das mulheres na política. Especificamente, se os respondentes acreditam que as mulheres devem assumir posições ativas e influentes na economia e na família, então é mais provável que eles apóiem a participação das mulheres na política. Para avaliar como as opiniões gerais sobre as mulheres na sociedade moldam as atitudes em relação às mulheres na esfera tradicionalmente masculina da política usamos duas variáveis: apoio às mulheres no local de trabalho e apoio à participação das mulheres nas decisões familiares.

Nosso segundo conjunto de hipóteses diz respeito aos exemplos das elites. Os líderes políticos emitem provavelmente uma variedade de sinais sobre como eles pensam a organização da sociedade e como a política deveria funcionar. Por exemplo: se os líderes políticos tomam medidas específicas, bem divulgadas para promover a participação das mulheres na política, ou simplesmente usam uma linguagem mais igualitária, essas ofertas práticas e simbólicas de inclusão podem promover a aceitação mais ampla e o apoio ao envolvimento político das mulheres. Ao contrário, a exclusão das mulheres de postos políticos importantes ou o uso de uma retórica machista podem encorajar atitudes mais sexistas do público em geral. Além disso, esses exemplos da elite provavelmente moldam as atitudes de gente como ativistas e membros de partidos, que estão especialmente ligados e afinados com a área política.

A fim de dar conta desse tipo de influência da elite sobre os respondentes, incorporamos medidas de conexão política em nossa análise das atitudes em relação às mulheres na política. Usamos a afiliação partidária como uma variável independente que nos permite avaliar como os laços dos respondentes com a política e, especificamente, a afinidade deles com as elites políticas moldam sua opinião sobre as mulheres na política em diferentes pontos do tempo. Em geral, esperamos que as pessoas com laços partidários mais fortes sejam mais influenciadas por mudanças substantivas ou simbólicas das posições da elite em questões pertinentes aos papéis das mulheres. Mais especificamente, no caso da República Dominicana, prevemos um certo padrão de mudança ao longo do tempo na natureza da influência da elite sobre as opiniões daqueles que possuem fortes laços partidários. Durante os primeiros anos do período analisado, as elites políticas dominicanas tomaram medidas que poderiam ser interpretadas como de promoção da participação das mulheres na política. Os fundos para a Diretoria Geral da Promoção da Mulher (DGPM), que foi depois convertida em Secretaria de Estado da Mulher (SEM), com nível de ministério, aumentaram durante os anos 90 (CEDAW, 1998). ${ }^{6}$ Em 1997, o congresso aprovou duas leis significativas que

\footnotetext{
6 A DGPM é uma agência criada em 1982 que funciona dentro da esfera de ação do Ministério da Presidência (HTUN, 1998).
} 
promoviam os direitos das mulheres. A primeira estabeleceu um sistema de cotas nas eleições: $25 \%$ dos candidatos às eleições para as assembléias municipais e para a Câmara de Deputados deveriam ser do sexo feminino. A segunda, a lei contra a violência intrafamiliar (Lei 24-97), criou proteções contra a violência doméstica, pondo em prática o compromisso assumido pelo país na Convenção Interamericana sobre a Prevenção, Punição e Erradicação da Violência contra as Mulheres, assinada pela República Dominicana em 1995 (CEDAW, 1998). Em 2000, novas leis aumentaram a cota de candidatas às eleições legislativas de 25 para $33 \%$ e também exigiram que os candidatos masculinos e femininos precisariam alternar suas posições nas listas partidárias, a fim de assegurar mais a eqüidade, ao mesmo tempo em que se determinava que uma mulher devia ser indicada pelos partidos para o cargo de prefeita ou vice-prefeita. ${ }^{7}$ Ao longo dos anos 90, as elites políticas da República Dominicana, lideradas por coalizões de legisladoras e líderes femininos da sociedade civil, fizeram progressos na defesa das questões femininas, promovendo o respeito pelas mulheres na família, na sociedade e na política (HTUN, 1998). Portanto, as pessoas que seguiam as elites durante esse período podem ter sido influenciadas pela maior aceitação do envolvimento das mulheres na política. Desse modo, esperamos que os respondentes das pesquisas de 1994, 1997 e 2001 que têm laços partidários e, portanto, maior probabilidade de conexão com a política e seguir a liderança das elites políticas, tenham opiniões mais positivas sobre a participação das mulheres do que aqueles que não têm essa ligação forte com as elites.

Por outro lado, é provável que, em 2004, os respondentes com laços partidários tivessem menos compromisso com o envolvimento político das mulheres. Durante a campanha presidencial de maio de 2004, houve uma onda de retórica machista, promovida pelo discurso mais inflamado que caracterizou a presidência de Hipólito Mejía. Essa retórica pode ter minado alguns dos avanços em atitudes relativas às mulheres ocorridos nos anos 90. Até a vice-presidenta Milagros Ortiz Bosch, conhecida por seu compromisso com as lutas femininas, engajou-se na retórica machista quando declarou em um grande comício de apoio à reeleição de Hipólito Mejía que o país precisava de um "homem com calças" para governar. Em conseqüência da promoção de atitudes machistas pelas elites políticas, esperamos que os membros de partidos sejam provavelmente influenciados pelas elites se inclinem menos do que antes a apoiar a participação das mulheres na política. Além

\footnotetext{
7 A eficácia da lei de cotas de gênero, no entanto, foi fortemente reduzida porque outras mudanças da legislação eleitoral feitas na época diminuíram o tamanho dos distritos eleitorais maiores e mudaram as eleições proporcionais de lista fechada para lista aberta. Em conseqüência, em 2002 não houve um aumento do número de mulheres eleitas para a Câmara de Deputados em comparação com 1998; em ambos os anos, ficou em $16 \%$.
} 
disso, na análise, fizemos interagir os laços partidários dos respondentes com o gênero a fim de avaliar se as sugestões das elites têm efeitos distintos entre homens e mulheres. ${ }^{8}$

O terceiro grupo de fatores que consideramos potencialmente significativos na moldagem de atitudes em relação às mulheres na política envolve as experiências de vida dos respondentes. Na análise, levamos em conta uma série de características sócio-demográficas que podem afetar o modo como as pessoas vêem a relação entre mulheres e política. Em primeiro lugar, incluímos o gênero dos respondentes como variável independente, com a expectativa de que nossa conclusão de que os homens provavelmente apóiam menos a participação das mulheres, em particular quando a diferença de gênero moderna emerge no século XXI (Tabela 1), seja sustentada nessa análise multivariada. Examinamos o impacto potencial dos efeitos geracionais explorando as diferenças entre grupos etários. A instrução também é incorporada como uma variável independente porque prevemos que as pessoas com nível educacional mais alto terão opiniões menos conservadoras dos papéis das mulheres. Além disso, incluímos termos de interação entre idade e gênero e entre instrução e gênero, ${ }^{9}$ que nos permitem determinar se esses fatores têm efeitos diferenciais entre homens e mulheres. Por exemplo, é possível que a instrução possa causar um efeito mais forte entre as mulheres porque elas talvez aceitem com mais facilidade as idéias igualitárias que os níveis educacionais mais altos supostamente promovem. Por fim, incluímos controles para situação marital e situação socioeconômica. ${ }^{10}$

\footnotetext{
${ }^{8}$ As variáveis que são componentes de termos de interação aqui (gênero, filiação partidária e simpatias partidárias) foram centradas antes de calcular os termos de interação, e as versões centradas dessas variáveis estão incluídas na análise apresentada adiante.

${ }^{9}$ As variáveis que são componentes de termos de interação aqui (gênero, grupo etário e instrução) foram centradas antes de calcular os termos de interação, e as versões centradas dessas variáveis estão incluídas na análise apresentada adiante.

10 Em algumas versões da análise, consideramos também o efeito da filiação religiosa (católica, outra ou sem filiação religiosa). A filiação religiosa não tem influência significativa sobre a escala de atitudes em relação às mulheres nas quatro pesquisas, nem sua inclusão ou exclusão altera os resultados relativos a outras variáveis.
} 
Análise das atitudes em relação às mulheres na política

A Tabela 4 apresenta os resultados da análise de regressão das atitudes em relação à participação das mulheres na política para as pesquisas realizadas entre 1994 e 2004. No total, o poder de explicação do modelo parece forte, com valores de $\mathrm{R}^{2}$ de pelo menos 0,19 para cada uma das análises; o ajuste do modelo é melhor em 1994 e pior em 2001. Nas quatro pesquisas, o apoio às mulheres no local de trabalho e o apoio à participação das mulheres nas decisões domésticas têm efeitos positivos significativos e consideráveis sobre o apoio às mulheres na política. Os respondentes que achavam que as mulheres deveriam poder trabalhar se assim escolhessem pontuaram perto de um ponto a mais na escala das atitudes em relação às mulheres na política do que aqueles que julgavam que as mulheres só deveriam trabalhar se a renda do homem fosse insuficiente. Observa-se a maior influência em 1997 e a menor em 2004, mas em todos os anos o efeito é grande e significativo no nível de 0,01. A influência das opiniões sobre o papel das mulheres no lar também é substancial. A idéia de que as mulheres devem se envolver nas decisões domésticas, como parceiro igual ou como a principal responsável pelas decisões, está associada com visões mais igualitárias do envolvimento das mulheres na política. Particularmente notável é que o pensamento de que ambos os parceiros devem participar das decisões domésticas, em oposição a somente o homem, resulta em um aumento de quase um ponto inteiro na escala da variável dependente (0,98 pontos em 1994, 0,95 em 1997, 0,61 em 2001 e 0,80 em 2004). Esses resultados indicam que, de um modo importante e significativo, as atitudes gerais quanto aos papéis das mulheres na família e na sociedade moldam opiniões mais específicas sobre as mulheres na política. 
KELLY, J.M.; ESPINAL, R.; HARTLYN, J. Diferenças de gênero na República Dominicana....

Tabela 4

Atitudes em relação às mulheres na política na República Dominicana, 1994-2004

\begin{tabular}{|c|c|c|c|c|}
\hline Variáveis independentes & 1994 & 1997 & 2001 & 2004 \\
\hline Apóia trabalho das mulheres & $\begin{array}{c}0,91^{* *} \\
(0,07)\end{array}$ & $\begin{array}{c}0,96 * * \\
(0,09)\end{array}$ & $\begin{array}{c}0,92^{* *} \\
(0,07)\end{array}$ & $\begin{array}{c}0,63 * * \\
(0,08)\end{array}$ \\
\hline \multicolumn{5}{|l|}{ Decisões domésticasa } \\
\hline Mulheres devem decidir & $\begin{array}{c}0,75^{\star *} \\
(0,17)\end{array}$ & $\begin{array}{c}0,89 * * \\
(0,14)\end{array}$ & $\begin{array}{c}0,45^{* *} \\
(0,12)\end{array}$ & $\begin{array}{c}0,18 \\
(0,14)\end{array}$ \\
\hline Ambos devem decidir & $\begin{array}{c}0,98 * * \\
(0,08)\end{array}$ & $\begin{array}{c}0,95 * * \\
(0,07)\end{array}$ & $\begin{array}{c}0,61 * * \\
(0,07)\end{array}$ & $\begin{array}{c}0,80 \text { ** } \\
(0,07)\end{array}$ \\
\hline \multicolumn{5}{|l|}{ Identificação com partidob } \\
\hline Membro de partido & $\begin{array}{c}0,32 * * \\
(0,08)\end{array}$ & $\begin{array}{l}0,23^{*} \\
(0,11)\end{array}$ & $\begin{array}{c}0,14 \\
(0,09)\end{array}$ & $\begin{array}{l}-0,15 \\
(0,08)\end{array}$ \\
\hline Membro*feminino & $\begin{array}{c}0,05 \\
(0,19)\end{array}$ & $\begin{array}{c}0,11 \\
(0,17)\end{array}$ & $\begin{array}{l}-0,32^{*} \\
(0,16)\end{array}$ & $\begin{array}{c}0,20 \\
(0,17)\end{array}$ \\
\hline Simpatizante & $\begin{array}{c}0,06 \\
(0,07)\end{array}$ & $\begin{array}{c}0,03 \\
(0,07)\end{array}$ & $\begin{array}{c}0,02 \\
(0,07)\end{array}$ & $\begin{array}{l}-0,06 \\
(0,07)\end{array}$ \\
\hline Simpatizante ${ }^{\star}$ feminino & $\begin{array}{l}-0,15 \\
(0,15)\end{array}$ & $\begin{array}{l}-0,02 \\
(0,15)\end{array}$ & $\begin{array}{l}-0,05 \\
(0,14)\end{array}$ & $\begin{array}{c}0,25 \\
(0,13)\end{array}$ \\
\hline Feminino & $\begin{array}{c}0,03 \\
(0,07)\end{array}$ & $\begin{array}{c}0,02 \\
(0,07)\end{array}$ & $\begin{array}{c}0,11 \\
(0,06)\end{array}$ & $\begin{array}{c}0,22 * * \\
(0,06)\end{array}$ \\
\hline Grupo etário & $\begin{array}{l}0,03^{*} \\
(0,01)\end{array}$ & $\begin{array}{l}0,03^{*} \\
(0,01)\end{array}$ & $\begin{array}{l}0,03^{*} \\
(0,01)\end{array}$ & $\begin{array}{c}0,01 \\
(0,01)\end{array}$ \\
\hline Grupo etário*feminino & $\begin{array}{l}-0,04 \\
(0,02)\end{array}$ & $\begin{array}{l}-0,05^{*} \\
(0,02)\end{array}$ & $\begin{array}{c}-0,08 * * \\
(0,02)\end{array}$ & $\begin{array}{c}-0,05^{* *} \\
(0,02)\end{array}$ \\
\hline Instrução & $\begin{array}{c}0,21 * * \\
(0,03)\end{array}$ & $\begin{array}{c}0,12 * * \\
(0,03)\end{array}$ & $\begin{array}{c}0,12^{* *} \\
(0,02)\end{array}$ & $\begin{array}{c}0,14 * * \\
(0,02)\end{array}$ \\
\hline Instrução*feminino & $\begin{array}{c}0,13^{* *} \\
(0,04)\end{array}$ & $\begin{array}{c}0,03 \\
(0,04)\end{array}$ & $\begin{array}{c}0,05 \\
(0,04)\end{array}$ & $\begin{array}{c}0,03 \\
(0,04)\end{array}$ \\
\hline Situação socioeconômica & $\begin{array}{l}0,02^{* *} \\
(0,006)\end{array}$ & $\begin{array}{c}0,007 \\
(0,007)\end{array}$ & $\begin{array}{c}0,005 \\
(0,006)\end{array}$ & $\begin{array}{c}0,007 \\
(0,006)\end{array}$ \\
\hline Casada(o)/unida(o) & $\begin{array}{c}-0,19 * * \\
(0,07)\end{array}$ & $\begin{array}{c}0,02 \\
(0,06)\end{array}$ & $\begin{array}{l}-0,08 \\
(0,06)\end{array}$ & $\begin{array}{c}0,01 \\
(0,06)\end{array}$ \\
\hline Constante & $\begin{array}{c}1,60^{* *} \\
(0,08)\end{array}$ & $\begin{array}{c}2,06 * * \\
(0,09)\end{array}$ & $\begin{array}{c}2,72^{* *} \\
(0,10)\end{array}$ & $\begin{array}{r}2,24 \text { ** } \\
(0,10)\end{array}$ \\
\hline R-quadrado & 0,34 & 0,25 & 0,19 & 0,20 \\
\hline Significância do modelo & 0,00 & 0,00 & 0,00 & 0,00 \\
\hline Número de observações & 2095 & 2365 & 2912 & 4024 \\
\hline
\end{tabular}


Os exemplos das elites parecem ter uma influência importante nas atitudes dos respondentes em relação à participação das mulheres na política. E para avaliar esse impacto, incluímos variáveis dummy para filiação a partidos e simpatias partidárias; aqueles sem filiação partidária servem como categoria de referência. ${ }^{11}$ Além disso, interagimos laços partidários com gênero a fim de determinar se os efeitos dos exemplos da elite são diferentes entre mulheres e homens. Examinando a seção "Identificação com partido" da Tabela 4, podemos ver imediatamente que os respondentes de ambos os gêneros que são apenas simpatizantes partidários não apresentam atitudes em relação às mulheres na política que sejam significativamente diversas daqueles que não simpatizam com nenhum partido político. Porém, encontramos que a filiação a um partido tem uma influência significativa sobre as opiniões dos respondentes sobre participação política das mulheres. Ademais, a natureza dessa influência varia de pesquisa para pesquisa em um padrão que reflete algumas das predições que fizemos levando em conta a natureza cambiante das sugestões das elites sobre o papel das mulheres na política e na sociedade dominicana.

A primeira linha da Tabela 5 decompõe os efeitos da filiação partidária sobre as atitudes em relação às mulheres na política entre respondentes do sexo feminino e do sexo masculino. Podemos ver que, tal como esperado em 1994, essa filiação produz posições de mais apoio ao envolvimento político das mulheres nos dois subgrupos. As mulheres que tinham filiação partidária pontuaram 0,34 pontos a mais na escala de mulheres na política do que as mulheres que não tinham filiação, e os filiados do sexo masculino pontuaram 0,29 pontos a mais na escala do que os não filiados. Em 1997, o efeito da filiação partidária diminuiu - significante somente no nível 0,10 para as mulheres e não significativo para os homens. ${ }^{12}$ Não obstante, a influência é positiva na direção esperada. Em 2001, novamente observamos uma relação positiva entre filiação partidária e apoio ao envolvimento das mulheres na política, mas aqui o efeito só é significativo entre os homens. Porém, três anos depois, a natureza da influência das sugestões da elite parece ter mudado consideravelmente.

\footnotetext{
11 Nas pesquisas de 1994, 1997 e 2001, perguntou-se aos respondentes somente se pertenciam ou simpatizavam com um partido político, então não pudemos distinguir entre filiados e simpatizantes dos diferentes partidos. Porém, a pesquisa de 2004 possibilita distinguir os membros dos três principais partidos do país, PLD, PRD e PRSC. Em análise não mostrada aqui, não encontramos diferenças notáveis entre membros dos diferentes partidos em suas atitudes em relação às mulheres (em comparação com respondentes que não indicaram nenhuma filiação). O único grupo distinto foram os simpatizantes do PRSC (mas não filiados) que apresentaram um pouco mais de apoio à participação política das mulheres do que os outros grupos.

12 Os testes de significância são bilaterais; se usarmos testes unilaterais, então o efeito para as mulheres é claramente significante no nível de 0,05 e o efeito para os homens é marginalmente significante no nível de 0,10.
} 
KELLY, J.M.; ESPINAL, R.; HARTLYN, J. Diferenças de gênero na República Dominicana....

Até 2001, a filiação partidária aumentava o apoio às mulheres na política. Mas na pesquisa de 2004, essa filiação tem um efeito negativo sobre as posições dos homens na escala de atitudes em relação às mulheres, resultado que reflete nossas expectativas quanto ao padrão da influência da elite ao longo do período 2000-2004, durante o governo de Mejía. É interessante também observar que embora os homens continuem a ser influenciados pelos exemplos da elite ao longo de todo o período, as opiniões das filiadas a partidos nas pesquisas de 2001 e 2004 não sofrem essa influência, talvez porque dinâmicas mais amplas socioeconômicas e culturais relacionadas com gênero se enraizaram mais entre as mulheres do que entre os homens. Em ambas as pesquisas, as mulheres em conjunto apresentam uma probabilidade significativamente maior de apoiar a participação política das mulheres.

Tabela 5

Atitudes em relação às mulheres na política: efeitos diferenciais entre gêneros

\begin{tabular}{|c|c|c|c|c|c|c|c|c|}
\hline \multirow{2}{*}{ Variável } & \multicolumn{2}{|c|}{1994} & \multicolumn{2}{|c|}{1997} & \multicolumn{2}{|c|}{2001} & \multicolumn{2}{|c|}{2004} \\
\hline & feminino & masculino & feminino & masculino & feminino & masculino & feminino & masculino \\
\hline $\begin{array}{l}\text { Filiação a } \\
\text { partido }\end{array}$ & $\begin{array}{c}0,34 * \star \\
(0,12)\end{array}$ & $\begin{array}{l}0,29 * \\
(0,13)\end{array}$ & $\begin{array}{c}0,29 \dagger \\
(0,15)\end{array}$ & $\begin{array}{c}0,18 \\
(0,13)\end{array}$ & $\begin{array}{l}0,002 \\
(0,11)\end{array}$ & $\begin{array}{c}0,33 * \star \\
(0,13)\end{array}$ & $\begin{array}{c}-0,06 \\
(0,12)\end{array}$ & $\begin{array}{c}-0,26 * \\
(0,11)\end{array}$ \\
\hline $\begin{array}{l}\text { Grupo } \\
\text { etário }\end{array}$ & $\begin{array}{c}0,01 \\
(0,02)\end{array}$ & $\begin{array}{c}0,05 * \star \\
(0,02)\end{array}$ & $\begin{array}{c}-0,001 \\
(0,02)\end{array}$ & $\begin{array}{c}0,05 * * \\
(0,02)\end{array}$ & $\begin{array}{c}-0,005 \\
(0,01)\end{array}$ & $\begin{array}{c}0,07 * * \\
(0,02)\end{array}$ & $\begin{array}{c}-0,01 \\
(0,01)\end{array}$ & $\begin{array}{c}0,04 * * \\
(0,01)\end{array}$ \\
\hline Instrução & $\begin{array}{c}0,27 * \star \\
(0,03)\end{array}$ & $\begin{array}{c}0,15 * * \\
(0,03)\end{array}$ & $\begin{array}{c}0,13 * * \\
(0,03)\end{array}$ & $\begin{array}{c}0,10 * * \\
(0,03)\end{array}$ & $\begin{array}{c}0,14 * * \\
(0,03)\end{array}$ & $\begin{array}{c}0,09 * * \\
(0,03)\end{array}$ & $\begin{array}{c}0,16 * * \\
(0,03)\end{array}$ & $\begin{array}{c}0,13 * * \\
(0,01)\end{array}$ \\
\hline
\end{tabular}

Nota: Erros padrão estão entre parênteses. ** $p \leq 0,01 ;{ }^{*} p \leq 0,05 ;{ }^{\dagger} p \leq 0,10$. Testes de significância são bilaterais. A significância indica que o efeito da variável na coluna da esquerda é significante dentro do grupo de gênero no cabeçalho da coluna associada, controlando-se as outras variáveis no modelo registrado na Tabela 4 . *

Durante a década de 1990 e a virada para o século XXI, a ligação e a afinidade com as elites políticas levaram os dominicanos a apoiar mais a participação das mulheres na política. Os líderes políticos e da sociedade civil tomaram medidas importantes para proteger os direitos das mulheres e estimular a sua participação na política. Essa forma visível de apoio das elites ao envolvimento político feminino promoveu um apoio similar entre os dominicanos que tinham laços mais próximos com esses líderes - os que tinham filiação partidária. Por outro lado, as elites políticas adotaram uma retórica fortemente machista na campanha presidencial de 2004 e, portanto, desestimularam o respeito pelo envolvimento político das mulheres. Isso serviu para prejudicar o apoio às mulheres na política, em particular entre os homens filiados a partidos, que podem ter um compromisso menos firme com o ideal de envolvimento das mulheres e, portanto, ser mais suscetíveis à influência da elite nessa questão. 
O último conjunto de variáveis que consideramos nesta análise são fatores sócio-demográficos que podem promover atitudes favoráveis ou não ao envolvimento das mulheres na política. Consideramos gênero, idade, instrução, situação socioeconômica e situação marital. Como mostra a Tabela 4, em média, as respondentes mulheres nas pesquisas de 1994 e 1997 apresentam a mesma probabilidade de apoiar o envolvimento político das mulheres que os respondentes homens. Porém, nos anos seguintes, vemos uma progressão no sentido de uma diferença de gênero moderna, que é marginalmente significativa em 2001 e claramente significativa em 2004, mesmo quando se controlam outros fatores importantes, como atitudes gerais em relação aos papéis das mulheres. No final do período, as mulheres estão muito mais inclinadas do que os homens a apoiar a participação política feminina. Além disso, o efeito de ser mulher é particularmente forte e significativo entre as respondentes mais jovens e mais instruídas. Com efeito, a interação entre instrução e gênero é tão forte que em todos os anos, exceto 1997, ser mulher tem uma influência positiva e significativa entre os respondentes com pelo menos um pouco de educação secundária. ${ }^{13}$

Desse modo, idade e educação influenciam bastante a escala das atitudes em relação às mulheres na política; ademais, essa influência varia entre mulheres e homens. As segunda e terceira linhas da Tabela 5 apresentam os efeitos desses dois fatores sócio-demográficos entre homens e entre mulheres nas quatro pesquisas. Enquanto a idade não apresenta nenhum efeito entre as respondentes do sexo feminino em qualquer ano, os do sexo masculino apóiam cada vez mais a participação das mulheres na política à medida que envelhecem. Nas quatro pesquisas, o coeficiente para idade entre os homens está em torno de 0,05 (variando de 0,04 a 0,07), indicando que os homens ganham cerca de 0,05 pontos

\footnotetext{
13 Em 2001, o efeito de ser mulher é significante somente de forma marginal no nível de 0,10, com dois testes bilaterais, mas é claramente significante no nível de 0,01 para as mulheres que não são filiadas a partidos. Em 1994, as mulheres que receberam pelo menos alguma educação secundária pontuam significativamente mais na escala de atitudes em relação às mulheres do que os homens de instrução equivalente. Em 1997, ser do sexo feminino não apresenta efeito significativo, independente de idade ou instrução. Em 2001, ser mulher tem uma influência positiva e significativa sobre as atitudes em relação à participação política das mulheres entre aquelas que tem pelo menos alguma educação secundária e entre as que têm menos de 40 anos de idade. Ser do sexo feminino não tem efeito significativo sobre as respondentes com instrução apenas primária e sobre aquelas que estavam entre 40 e 59 anos de idade. A mulheres mais velhas da pesquisa, com 60 ou mais anos, apresentaram uma propensão significativamente menor de apoiar a participação política das mulheres do que os homens da mesma faixa etária. Em 2004, ser do sexo feminino tem um efeito positivo e significativo entre todos os respondentes que tiveram pelo menos alguma instrução; somente os que nunca freqüentaram a escola o fato de ser mulher não influencia em nada. Além disso, tal como em 1994 e 2001, a diferença de gênero aumenta em graus de educação mais altos, de tal modo que ser mulher tem um efeito muito mais positivo entre aquelas com educação superior do que entre as que freqüentaram apenas a escola primária ou secundária.
} 
na escala de atitudes em relação às mulheres na política a cada cinco anos de envelhecimento. A Figura 1 representa com clareza esse efeito e podemos ver que se todo o resto for mantido igual, homens com mais de 65 anos pontuam meio ponto a mais na escala de seis pontos do que os homens que têm menos de 19 anos. Por exemplo, em 2001, o modelo prediz que homens com menos de 19 anos pontuarão 2,8 na escala de atitudes em relação às mulheres na política, enquanto os homens com mais de 65 pontuarão 3,3.

Figura 1

Valores esperados na escala de atitudes em relação às mulheres, por gênero e idade

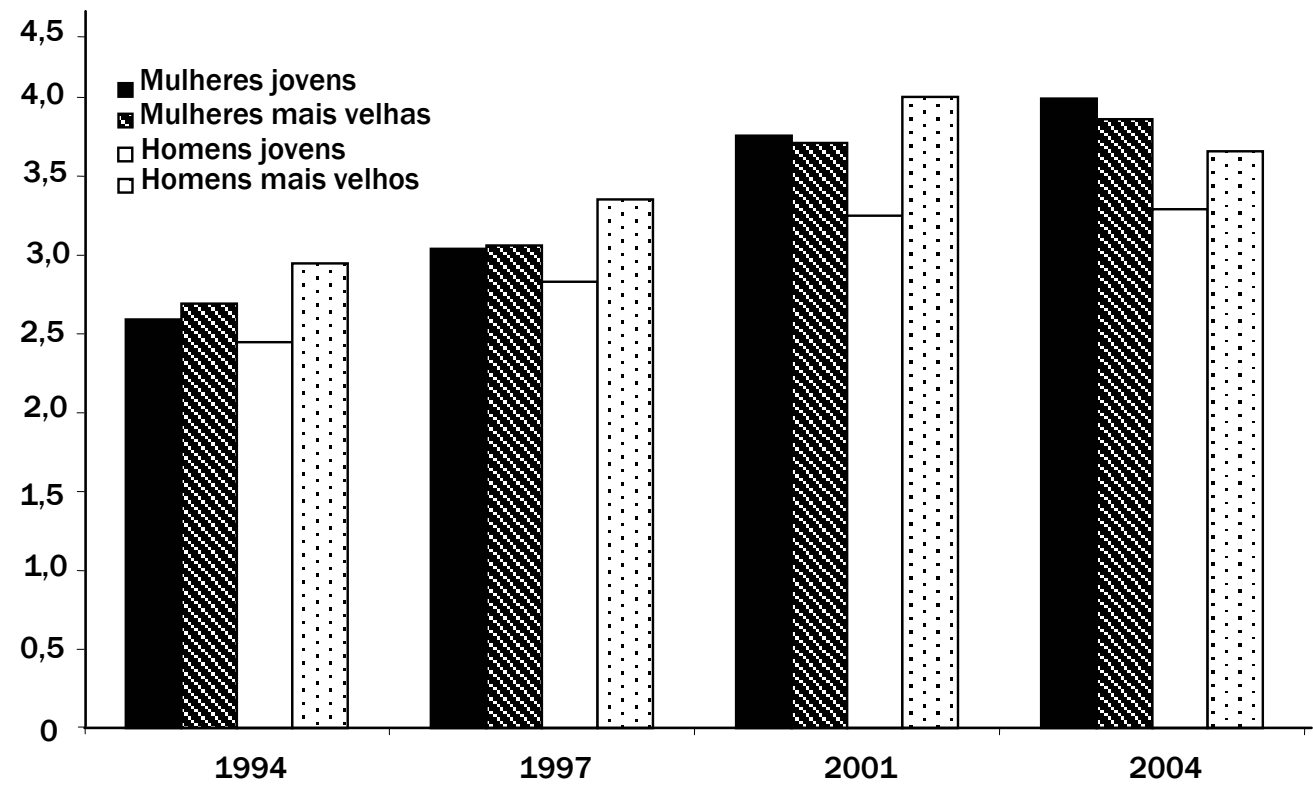

A instrução exerce uma influência significativa e substancial sobre o apoio às mulheres na política. Como podemos ver na Tabela 5, o efeito é significante para ambos os gêneros, mas é particularmente forte para as mulheres. Em todas as pesquisas, as mulheres pontuam pelo menos 0,13 mais do que os homens na escala de atitudes em relação às mulheres na política para cada nível adicional de instrução alcançada. A Figura 2 representa a natureza desses efeitos graficamente. Podemos ver que as mulheres sem instrução não apresentam escores particularmente altos na escala de atitudes em relação às mulheres na política, mas 
as mulheres com alta instrução pontuam mais do que todas as outras categorias de respondentes em todas as quatro pesquisas. Por exemplo, em 1994, quando a influência é especialmente vigorosa, as mulheres com pelo menos alguma instrução universitária pontuam 3,4 na escala, enquanto as mulheres sem nenhuma instrução pontuam apenas 2,0; homens sem instrução pontuam 2,4 e até homens com educação superior pontuam apenas 3,0. Indica também que a instrução promove atitudes igualitárias entre as mulheres acima e além do efeito que tem sobre os homens. Esse resultado indica que, em geral, educar o povo seria uma excelente maneira de o governo agir para gerar um aumento do apoio à participação política das mulheres.

Figura 2

Valores esperados na escala de atitudes em relação às mulheres por gênero e instrução

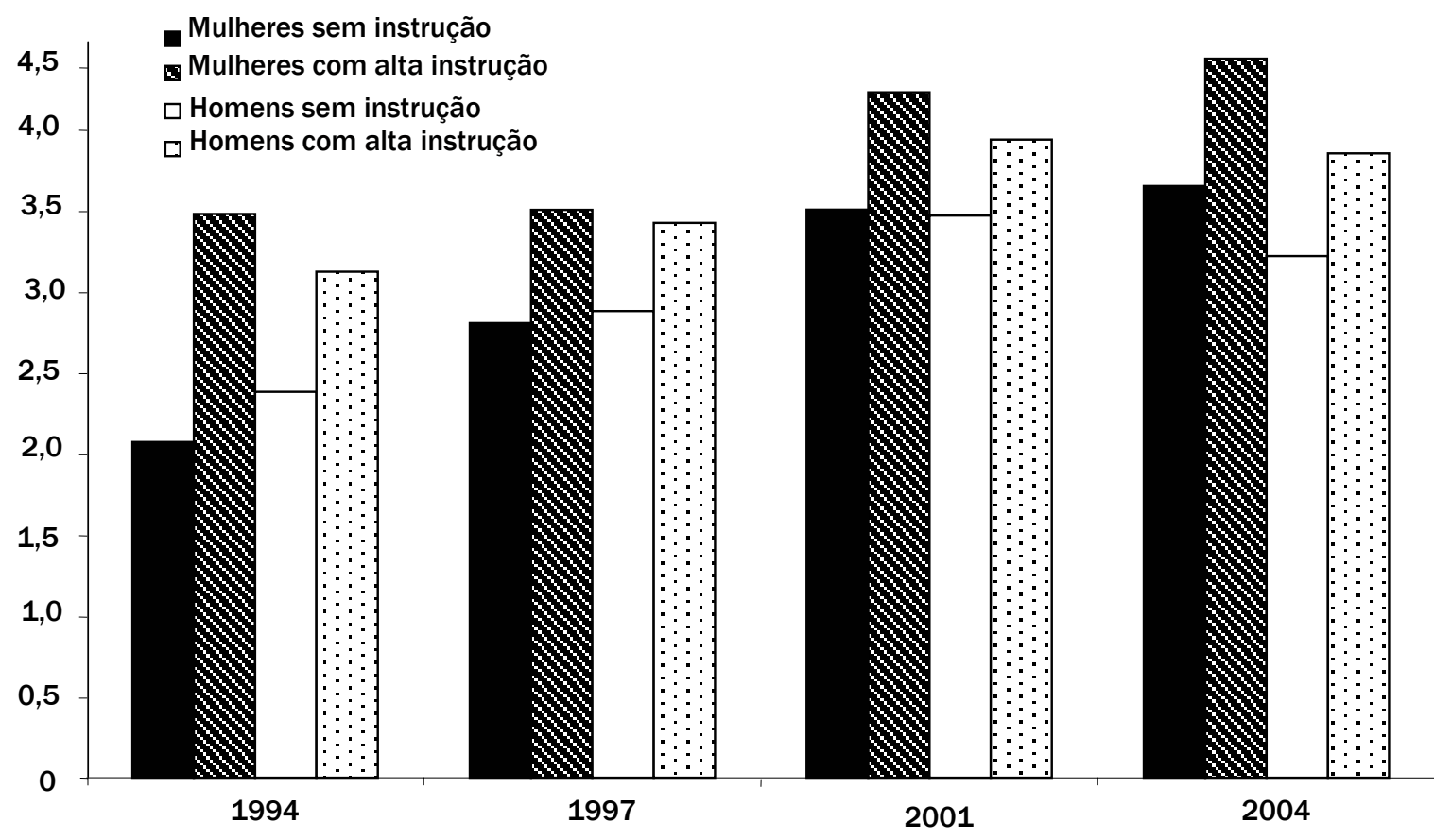


Por fim, consideramos a influência da situação socioeconômica e marital sobre o apoio às mulheres na política. Só encontramos efeitos significativos desses fatores em 1994, quando a situação socioeconômica apresenta uma relação positiva com as opiniões igualitárias da participação política, enquanto que a situação marital tem uma relação negativa. Nas três pesquisas posteriores, esses efeitos diminuem e não são mais significativos quando se controlam outros fatores. ${ }^{14}$ Porém, é interessante observar que a instrução e a situação socioeconômica estão altamente correlacionadas; portanto, se tirarmos a instrução do modelo, a situação socioeconômica tem uma influência positiva e significativa sobre a escala de atitudes em relação às mulheres em todos os quatro anos. A magnitude desse efeito é da ordem de 0,02, significante no nível de 0,01. ${ }^{15}$

Tomadas em conjunto, as análises das atitudes em relação à participação das mulheres na política apontam para vários fatores importantes para a compreensão das atitudes dos dominicanos. Particularmente importantes são as atitudes gerais em relação aos papéis das mulheres: atitudes mais igualitárias levam a mais apoio à participação política das mulheres. Vimos também que os exemplos da elite causam um impacto significativo naqueles que possuem ligações estreitas com o sistema político através de filiação partidária e que os homens são particularmente vulneráveis a mudanças nas posições da elite. Portanto, as idéias que as elites políticas promovem quanto à participação das mulheres na política têm uma influência significativa sobre o apoio dos cidadãos comuns ao igualitarismo de gênero na política. Por fim, a instrução, em especial entre as mulheres, e a idade, embora apenas entre os homens, também mostram um aumento substancial de apoio dos respondentes ao envolvimento político das mulheres.

\footnotetext{
14 Consideramos também a possibilidade de que a situação socioeconômica e a marital podem ter efeitos distintos em homens e mulheres. Portanto, realizamos outras análises, que não são mostradas aqui, nas quais fizemos interagir as duas situações com gênero. Não encontramos diferenças significativas entre mulheres e homens nos efeitos dessas duas variáveis.

15 Em nossa análise, consideramos também os efeitos que os fatores sócio-demográficos podem ter indiretamente por meio de sua influência sobre as opiniões mais gerais dos respondentes sobre os papéis das mulheres na sociedade e na família. Portanto, realizamos análises adicionais, tratando as atitudes dos respondentes em relação ao trabalho das mulheres e o papel delas nas decisões domésticas como variáveis dependentes. Na análise logit multivariada dessas duas variáveis, utilizamos como variáveis independentes os mesmos fatores sócio-demográficos da análise da escala de atitudes em relação às mulheres na política. Como era de se esperar, encontramos que sexo feminino, idade, instrução e situação socioeconômica mantêm geralmente relações positivas e significativas com o apoio ao trabalho das mulheres e à participação delas nas decisões domésticas. Esse resultado indica que esses fatores sócio-demográficos são importantes para compreender as opiniões dos dominicanos sobre mulheres na política devido a sua relação direta com essas atitudes, mas que os mesmos fatores têm influência indireta significativa por meio de seu papel na formação de atitudes mais gerais em relação aos papéis femininos. A situação marital não apresenta consistentemente efeitos significativos.
} 


\section{Explicações para o interesse por política}

Nessa segunda parte nosso foco recai sobre o interesse por política como variável dependente principal, porque buscamos explicar por que as pessoas se conectam com a esfera política e nela se engajam. Analisar o interesse por política é uma maneira excelente de avaliar essa ligação e determinar os fatores que podem ajudar a encorajar as pessoas a optar pela política, em vez de ficar fora dela. Para isso realizamos uma análise de regressão multivariada da escala de interesse por política de sete pontos desenvolvida acima.

Temos dois objetivos principais ao realizar essa análise. Primeiro, pretendemos determinar se a relação entre gênero e interesse por política observada na análise bivariada persiste ou não quando introduzimos controles para outros fatores que podem potencialmente confundir. Na análise da diferença de gênero em engajamento cívico e político, descobrimos que os homens se interessavam significativamente mais por política do que as mulheres nas quatro pesquisas, mas essa diferença diminuiu durante a década analisada. Ao realizar análises de regressão multivariada, podemos avaliar o quanto essa diferença de gênero tradicional em interesse por política é atribuível a outros fatores, tais como grau baixo de instrução das mulheres, e o quanto parece haver diferenças entre gêneros independentes desses efeitos. O segundo objetivo é explicar por que as pessoas desenvolvem um interesse por política e daí explicar por que podem existir diferenças entre gêneros. Além disso, podemos ter condições de descobrir se existem ou não diferenças no processo causal que explica o interesse por política entre as mulheres em comparação com os homens.

Além do gênero, consideramos três conjuntos de variáveis independentes que imaginamos terem influência sobre o interesse por política. 0 primeiro conjunto são medidas de motivações para se interessar por política, fatores que podem impulsionar pessoas que, de outro modo, não se preocupam com política a ter um interesse mais ativo por essa esfera. Consideramos a insatisfação com o desempenho do governo um fator que pode levar as pessoas e se engajarem mais na política. Nossa hipótese é que, se tudo na economia e na sociedade parece andar bem, então as pessoas terão menos necessidade de se preocupar com política. Ao contrário, a deficiência dos serviços básicos que as pessoas esperam do governo pode levá-las a se engajar mais na política. Para avaliar o papel potencial da insatisfação com o governo no aumento do interesse pela política, consideramos duas variáveis independentes: avaliação da execução de serviços e avaliações da economia. A avaliação dos serviços feita pelos respondentes é medida usando uma escala aditiva que vai de zero a sete, que combina as avaliações feitas por eles de sete serviços públicos: transporte, educação, hospitais, seguridade social, eletricidade, água potável e habitação acessível. Medimos as avaliações da economia usando um item 
que pedia aos respondentes para avaliar a situação econômica de suas famílias numa escala de cinco pontos que vai de muito ruim a muito boa.

Em segundo lugar, propomos a hipótese de que as pessoas mais integradas na vida pública apresentam maior probabilidade de se interessar por política. Portanto, consideramos a situação de emprego como um fator explicativo. Prevemos que as pessoas ativas no mercado de trabalho terão tanto a oportunidade como o ímpeto de se engajar na política. É provável que as pessoas que não estão empregadas se preocupem principalmente com a vida privada e sintam menos necessidade de se engajar na esfera pública da política. Além disso, as pessoas que não estão trabalhando apresentam menor probabilidade do que as empregadas de desenvolver conexões com outros indivíduos ou grupos que buscam ativamente o envolvimento na política. ${ }^{16}$

As variáveis sócio-demográficas constituem o terceiro grupo de fatores que consideramos como potencialmente associados ao interesse por política. Em geral, esperamos que, à medida que ficam mais maduras e mais instruídas e acumulam mais recursos, as pessoas também se engajam mais na política. Então incluímos idade, instrução e situação socioeconômica como variáveis independentes. Queremos também levar em conta a possibilidade de que esses fatores influenciem o interesse por política de homens e mulheres de modo diferente. Portanto, consideramos efeitos de interação entre gênero e cada um desses três fatores sóciodemográficos. ${ }^{17}$ Por fim, abrimos para a possibilidade de efeitos baseados na situação marital e no local de residência dos respondentes e incluímos casado versus solteiro ${ }^{18}$ e rural versus urbano como variáveis independentes na análise.

Examinando a Tabela 6 , podemos avaliar os resultados de nossa análise do interesse por política nas quatro pesquisas realizadas entre 1994 e 2004. O exame dos resultados indica que o gênero mantém uma relação estatisticamente significante com o interesse por política em todas as quatro, mesmo com a incorporação das outras variáveis independentes. As mulheres apresentam um interesse por política muito menor do que os homens. Por exemplo, em 1997, em média, as mulheres pontuaram 0,87 pontos a menos do que os homens na escala de interesse por política, mantendo-se todo o resto igual. Ademais, o gênero parece ter uma das influências mais substanciais de todas as variáveis do modelo. Porém,

\footnotetext{
${ }^{16}$ Consideramos a possibilidade de que o efeito da integração com a esfera pública, em outras palavras, o fato de estar empregado, poderia ser diferente entre homens e mulheres. Porém, as interações entre gênero e situação empregatícia, em modelos não exibidos aqui, não revelaram diferenças de gênero.

17 As variáveis que são componentes dos termos de interação aqui (gênero, faixa etária e instrução) foram centradas antes de calcular o termo de interação, e as versões centradas dessas variáveis estão incluídas na análise apresentada abaixo.

18 Aqueles que disseram que eram casados ou unidos pontuam um nesta variável, e as pessoas de todas as outras situações maritais (nunca casou, divorciado/separado, viúvo) pontuam zero.
} 
a diferença entre homens e mulheres diminui significativamente ao longo do período e, em 2004, as mulheres pontuam apenas 0,6 pontos a menos do que os homens na escala de interesse por política.

Tabela 6

Interesse por política na República Dominicana, 1994-2004

\begin{tabular}{|c|c|c|c|c|}
\hline Variáveis independentes & 1994 & 1997 & 2001 & 2004 \\
\hline Feminino & $\begin{array}{c}-0,81 * * \\
(0,10)\end{array}$ & $\begin{array}{c}-0,87 * * \\
(0,10)\end{array}$ & $\begin{array}{c}-0,64 * * \\
(0,08)\end{array}$ & $\begin{array}{c}-0,57 * * \\
(0,09)\end{array}$ \\
\hline Avaliação de serviços & $\begin{array}{c}-0,10 * * \\
(0,02)\end{array}$ & $\begin{array}{c}-0,03 \\
(0,02)\end{array}$ & $\begin{array}{c}-0,04 * \\
(0,02)\end{array}$ & $\begin{array}{c}0,02 \\
(0,02)\end{array}$ \\
\hline Avaliação econômica & $\begin{array}{c}-0,07 \\
(0,05)\end{array}$ & $\begin{array}{c}-0,08 \\
(0,05)\end{array}$ & $\begin{array}{c}0,05 \\
(0,04)\end{array}$ & $\begin{array}{c}-0,02 \\
(0,06)\end{array}$ \\
\hline Empregado & $\begin{array}{l}0,23 * \\
(0,10)\end{array}$ & $\begin{array}{c}0,04 \\
(0,10)\end{array}$ & $\begin{array}{l}0,18 * \\
(0,07)\end{array}$ & $\begin{array}{c}0,09 \\
(0,08)\end{array}$ \\
\hline Grupo etário & $\begin{array}{c}0,05 * * \\
(0,02)\end{array}$ & $\begin{array}{c}0,05 * * \\
(0,02)\end{array}$ & $\begin{array}{c}0,02 \\
(0,02)\end{array}$ & $\begin{array}{c}0,05 * * \\
(0,01)\end{array}$ \\
\hline Grupo etário*Feminino & $\begin{array}{c}-0,05 \\
(0,03)\end{array}$ & $\begin{array}{c}-0,05 \\
(0,03)\end{array}$ & $\begin{array}{c}-0,09 * * \\
(0,03)\end{array}$ & $\begin{array}{c}-0,13 * * \\
(0,03)\end{array}$ \\
\hline Instrução & $\begin{array}{c}0,29 * * \\
(0,04)\end{array}$ & $\begin{array}{c}0,39 * * \\
(0,03)\end{array}$ & $\begin{array}{c}0,33 * * \\
(0,03)\end{array}$ & $\begin{array}{c}0,33 * * \\
(0,03)\end{array}$ \\
\hline Instrução*Feminino & $\begin{array}{c}-0,05 \\
(0,05)\end{array}$ & $\begin{array}{c}-0,09 \\
(0,05)\end{array}$ & $\begin{array}{c}-0,04 \\
(0,05)\end{array}$ & $\begin{array}{c}-0,18 * \star \\
(0,06)\end{array}$ \\
\hline Situação socioeconômica & $\begin{array}{c}0,03 * * \\
(0,01)\end{array}$ & $\begin{array}{c}0,03 * * \\
(0,01)\end{array}$ & $\begin{array}{c}0,01 \\
(0,01)\end{array}$ & $\begin{array}{l}0,000 \\
(0,01)\end{array}$ \\
\hline Casada(o)/unida(o) & $\begin{array}{r}-0,001 \\
(0,09)\end{array}$ & $\begin{array}{c}0,07 \\
(0,09)\end{array}$ & $\begin{array}{c}-0,04 \\
(0,09)\end{array}$ & $\begin{array}{c}-0,06 \\
(0,08)\end{array}$ \\
\hline Rural & $\begin{array}{c}0,18 \\
(0,11)\end{array}$ & $\begin{array}{c}0,13 \\
(0,11)\end{array}$ & $\begin{array}{c}0,07 \\
(0,08)\end{array}$ & $\begin{array}{l}-0,10 \\
(0,08)\end{array}$ \\
\hline Constante & $\begin{array}{c}2,54 * * \\
(0,17)\end{array}$ & $\begin{array}{c}2,66 * * \\
(0,15)\end{array}$ & $\begin{array}{c}2,32 * \star \\
(0,17)\end{array}$ & $\begin{array}{c}2,64 * * \\
(0,16)\end{array}$ \\
\hline R-quadrado & 0,20 & 0,21 & 0,15 & 0,13 \\
\hline Significância do modelo & 0,00 & 0,00 & 0,00 & 0,00 \\
\hline Número de observações & 1738 & 1788 & 2228 & 3085 \\
\hline
\end{tabular}

Além dos efeitos de gênero, consideramos também a influência mobilizadora potencial da frustração com o desempenho do governo. Porém, a análise demonstra que as avaliações econômicas dos respondentes não causam impacto significativo no interesse por política. Avaliações negativas dos serviços públicos estão associadas com maior interesse por política em 1994 e 2001, mas não em 1997 e 2004. Portanto, a frustração com a economia não parece ter um efeito mobilizador 
e o desapontamento com os serviços públicos tem um impacto limitado. No conjunto, parece que o interesse por política é gerado apenas ocasionalmente em conseqüência da insatisfação das pessoas com o desempenho do governo.

Do mesmo modo, encontramos apoio limitado para a hipótese de que as pessoas integradas na esfera pública graças ao emprego ativo serão estimuladas a se interessar por política. Encontramos relações positivas substanciais e significativas entre estar empregado e níveis mais altos de interesse por política em 1994 e 2001, com o emprego levando a um aumento de quase um quarto de ponto em 1994. Porém, não encontramos conexão entre emprego e interesse por política nas pesquisas de 1997 e 2004.

Por fim, observamos que idade e instrução parecem, em média, ter influência positiva e significativa sobre o interesse por política. Porém, situação marital e local de residência não têm influência significativa em qualquer das quatro pesquisas. Em 1994 e 1997, a situação sócio-econômica tem um efeito positivo de 0,03 , que se traduz numa diferença de cerca de 0,75 pontos na escala de interesse por política entre os respondentes mais pobres e os mais ricos. No entanto, esse efeito se dissipa nas pesquisas de 2001 e 2004, nas quais não encontramos relação significativa entre situação socioeconômica e interesse por política.

$\mathrm{Na}$ análise final, incluímos também efeitos de interação com gênero para idade e instrução; não encontramos diferenças significativas entre mulheres e homens para os efeitos de situação socioeconômica e, portanto, excluímos esse termo de interação da análise apresentada aqui. A Tabela 7 exibe os efeitos diferenciais de idade e instrução separadamente para homens e mulheres. Com relação à idade, encontramos um efeito positivo e significativo sobre o interesse por política entre os homens, mas nenhuma diferença em interesse por política entre mulheres de idades diferentes. Esse resultado espelha exatamente o que descobrimos sobre os efeitos condicionais da idade nas atitudes em relação às mulheres na política, onde vimos que a idade não influencia entre as mulheres, mas tem um efeito positivo entre os homens. Esses resultados indicam que à medida que os dominicanos envelhecem, as diferenças tradicionais de gênero em interesse por política e atitudes em relação às mulheres aumentam porque os homens desenvolvem um interesse por política maior e se tornam mais tolerantes, mas as mulheres não. Isso sugere que a oportunidade para gerar maior interesse por política e igualitarismo entre as mulheres não se expande com a idade; ao contrário, é provável que suas atitudes de jovens adultas se mantenham pelo resto de suas vidas. O melhor momento para estimular as mulheres a se engajar na política e estimular o apoio à sua participação talvez seja quando ainda são crianças e jovens adultas. 
Tabela 7

Interesse por política: efeitos diferenciais entre gêneros

\begin{tabular}{|l|c|c|c|c|c|c|c|c|}
\hline \multirow{4}{*}{ Variável } & \multicolumn{2}{|c|}{1994} & \multicolumn{2}{c|}{1997} & \multicolumn{2}{c|}{2001} & \multicolumn{2}{c|}{2004} \\
\cline { 2 - 9 } & feminino & masculino & feminino & masculino & feminino & masculino & feminino & masculino \\
\hline Grupo etário & $\begin{array}{c}0,02 \\
(0,02)\end{array}$ & $\begin{array}{c}0,07 * * \\
(0,02)\end{array}$ & $\begin{array}{c}0,02 \\
(0,02)\end{array}$ & $\begin{array}{c}0,07 * * \\
(0,02)\end{array}$ & $\begin{array}{c}-0,02 \\
(0,02)\end{array}$ & $\begin{array}{c}0,07 * * \\
(0,02)\end{array}$ & $\begin{array}{c}-0,01 \\
(0,02)\end{array}$ & $\begin{array}{c}0,12^{* *} \\
(0,02)\end{array}$ \\
\hline Instrução & $\begin{array}{c}0,27^{* *} \\
(0,04)\end{array}$ & $\begin{array}{c}0,32 * * \\
(0,05)\end{array}$ & $\begin{array}{c}0,34 * * \\
(0,04)\end{array}$ & $\begin{array}{c}0,42 * * \\
(0,04)\end{array}$ & $\begin{array}{c}0,32 * * \\
(0,04)\end{array}$ & $\begin{array}{c}0,35 * * \\
(0,04)\end{array}$ & $\begin{array}{c}0,25 * * \\
(0,05)\end{array}$ & $\begin{array}{c}0,43^{* *} \\
(0,04)\end{array}$ \\
\hline
\end{tabular}

Nota: Erros padrão estão entre parênteses. ** $p \leq 0,01 ;{ }^{*} p \leq 0,05$. Testes de significância são bilaterais $A$ significância indica que o efeito da variável na coluna da esquerda é significante dentro do grupo de gênero no cabeçalho da coluna associada.

Na Tabela 7 observamos também que a instrução tem uma forte influência positiva no interesse por política em ambos os gêneros, como era nossa hipótese. Porém, vemos também indícios de que a diferença de gênero tradicional em interesse por política aumenta à medida que os dominicanos atingem graus mais altos de instrução. Embora tanto homens como mulheres desenvolvam um maior interesse por política à medida que ficam mais instruídos, o efeito da educação é maior entre os homens do que entre as mulheres. A diferença está presente em todas as quatro pesquisas, mas é mais notável em 2004, em que o coeficiente para os homens é de 0,43 pontos, mas o das mulheres é somente de 0,25 (ambos significativos no nível de 0,01). Na prática, isso significa que, em 2004, para cada nível adicional de instrução alcançada, o interesse dos homens pela política aumenta em 0,18 pontos mais do que o das mulheres. Essa diferença considerável entre os gêneros no efeito da instrução sugere que embora a educação promova em geral um maior engajamento político, há alguma coisa no processo educacional na República Dominicana que estimula mais os homens do que as mulheres a se interessar ativamente pela política. Como vimos acima, a instrução aumenta a tolerância para com a participação política das mulheres mais entre as mulheres do que entre os homens. Portanto, é provável que graus maiores de instrução aumentem as opiniões igualitárias de homens e mulheres, mas proporcionalmente mais entre as mulheres. Porém, a instrução, ao mesmo tempo em que aumenta o interesse por política de ambos os gêneros, tem maior influência nos homens. ${ }^{19}$

\footnotetext{
19 Nenhuma das pesquisas indica uma "diferença” de educação significante entre homens e mulheres.
} 


\section{Conclusão}

A análise dessas pesquisas indica que na República Dominicana, no período 1994-2004, elementos do que foi chamado de diferença de gênero tradicional continuam vigentes no país no que diz respeito a engajamento cívico, interesse por política e atitudes em relação à democracia. Ao mesmo tempo, essa diferença desapareceu em relação à participação em eleições e uma diferença de gênero moderna surgiu pela primeira vez no que diz respeito a atitudes em relação ao papel das mulheres na política. Contudo, nas opiniões sobre a participação das mulheres na política, o país sofreu um recuo em 2004 em comparação com 2001, demonstrando a sensibilidade dessas atitudes ao contexto político. Análises multivariadas destacam diferenças em membros de partidos políticos do sexo masculino em 2004 em comparação com anos anteriores consistentes com nossa predição, tendo em vista a mudança do clima político no país. Nossa análise mostra também que as atitudes positivas em relação às mulheres no local de trabalho e no âmbito doméstico influenciam as atitudes em relação à participação das mulheres na política. O que julgamos particularmente importante é a força da influência da instrução sobre as atitudes das mulheres de diferentes idades em relação ao papel delas na política, muito mais vigorosa do que no caso dos homens. Por outro lado, a idade tem um efeito positivo sobre os homens, o que não acontece com as mulheres.

No que tange ao interesse por política, talvez não seja surpreendente embora não seja menos perturbador - ver a persistência de uma diferença de gênero tradicional. Nesse caso, a educação tem um efeito positivo muito mais poderoso sobre os homens do que sobre as mulheres. E o envelhecimento também tem uma influência positiva sobre os homens, mas não sobre as mulheres.

Somente pesquisas futuras poderão nos dizer se as mulheres estão começando a experimentar um efeito positivo do envelhecimento similar ao dos homens à medida que entram cada vez mais na força de trabalho e talvez se engajem na política. Será útil também comparar esses resultados com aqueles de outros países da região e em outras áreas em desenvolvimento para ver se mostram efeitos diferenciais causados por idade e instrução semelhantes. 
Referências Bibliográficas

ASTELARRA, J. (ed.). Participación política de las mujeres. Madrid: Centro de Investigaciones Sociológicas, 1990.

AQUINO, J. A. Cuota femenina, circunscripciones electorales y listas de candidaturas (relatório de pesquisa). Santo Domingo: Centro de Estudios del Género, INTEC, 2003.

ALVAREZ, S. et al. Encountering Latin American and caribbean feminisms. Signs: Journal of Women in Culture \& Society, v. 28, n. 2, p. 537-579, 2002.

BÁEZ, C.; PAIEWONSKY, D. Género y ciudadanía (Relatório). Santo Domingo: Programa de Fortalecimiento de la Sociedad Civil, Instituto Tecnológico de Santo Domingo, 2000.

BERGERON, S. Political economy discourses of globalization and feminist politics. Signs: Journal of Women in Culture \& Society, v. 26, n. 4, p. 983-1007, 2001.

BRACE, L.; DAVIDSON, J. O. Minding the gap: general and substantive theorizing on power and exploitation. Signs: Journal of Women in Culture \& Society, v. 25, n. 4, p. 1046-1050, 2000.

BREA, R.; DUARTE, I. Entre la calle y la casa: las mujeres dominicanas y la cultura política a finales del siglo XX. Santo Domingo: Editora Búho, 1999.

BREA, R.; DUARTE, I.; SELIGSON, M. La democracia vulnerable: insatisfacción y desconfianza (1994-2004). Santo Domingo: Editora Búho, 2005.

BREHM, J.; RAHN, W. Individual-level evidence for the causes and consequences of social capital. American Journal of Political Science, v. 41, n. 3, p. 999-1023, 1997.

CITRIN, J.; GREEN, D. P. Presidential leadership and the resurgence of trust in government. British Journal of Political Science, v. 16, n. 4, p. 431-453, 1986.

COMMITTEE ON THE ELIMINATION OF DISCRIMINATION AGAINST WOMEN (CEDAW). Concluding observations of the committee on the elimination of the discrimination against women, Dominican Republic. United Nations Document A/53/38, 1998.

CORDERO, M. Mujer: participación política y procesos electorales (1986-1999). Santo Domingo: Editora Taller, 1991. 
KELLY, J.M.; ESPINAL, R.; HARTLYN, J. Diferenças de gênero na República Dominicana....

. La brega por la participación política, espacio de unidad de las mujeres. Estudios

Sociales, v. 29, n. 103, p. 39-48, 1996.

DUARTE, I.; BREA, R.; TEJADA H., R.; BÁEZ, C. Cultura política y democracia en República Dominicana (DEMOS 94). Santo Domingo: Pontificia Universidad Católica Madre y Maestra, 1996.

DUARTE, I.; BREA, R.; TEJADA H., R. Cultura política y democracia en la República Dominicana, 1997 (DEMOS 1997). Santo Domingo: Pontificia Universidad Católica Madre y Maestra, 1997.

DUARTE, I.; BREA, R. Hacia dónde va la democracia dominicana, 1994-2001 (DEMOS 2001). Santo Domingo: Pontificia Universidad Católica Madre y Maestra, 2002.

ESPINAL, R. Autoritarismo y democracia en la política Dominicana. San José, Costa Rica: IIDH. CAPEL, 1987.

. La sociedad civil mobilizada y las reformas democráticas en la República Dominicana.

Revista Espinal, v. 7, n. 21, p. 101-132, 2001.

ESPINAL, R.; GRASMUCK, S. Gender, households and Informal entrepreneurship in the Dominican Republic. Journal of Comparative Family Studies, v. 28, n. 1, p. 103-128, 1997.

ESPINAL, R.; HARTLYN, J. The Dominican Republic: the long and difficult struggle for democracy in the Dominican Republic. In: DIAMOND, L. et al. (ed.). Democracy in developing countries: Latin America. Boulder: Lynne Rienner, 1999.

ESPINAL, R.; HARTLYN, J.; KELLY, J. M. Performance still matters: explaining trust in government in the Dominican Republic. Comparative Political Studies, v. 39, n. 2, p. 200-223, 2005a.

. Democracia y género en la República Dominicana. In: CANDELARIO, G. E. B. (ed.). Miradas desencadenantes: Ios estudios de género en la República Dominicana al inicio del tercer milenio. Santo Domingo: Centro de Estudios de Género, INTEC, 2005b.

FIGUEIRAS, C. L. Feminismo en República Dominicana: balances y perspectivas. Género y Sociedad, v. 3, n. 2, p. 41-89, 1995.

FOLEY, M.; EDWARDS, B. The paradox of civil society. Journal of Democracy, v. 7, n. 3, p. 38 . 52, 1996. 
GRASMUCK, S.; ESPINAL, R. Market success or female autonomy? income, ideology, and empowerment among micro entrepreneurs in the Dominican Republic. Gender \& Society, v. 14 , n. 2, p. 231-255, 2000.

HARTLYN, J. The struggle for democratic politics in the Dominican Republic. Chapel Hill: University of North Carolina Press, 1998.

HASBÚN, J.; ARVELO, J. Poder y representación femenina. Santo Domingo: Participación Ciudadana, 2000.

HEKMAN, S. Truth and method: feminist standpoint theory revisited. Signs: Journal of Women in Culture and Politics, v. 22, n. 2, p. 341-365, 1997.

HETHERINGTON, M. The political relevance of political trust. The American Political Science Review, v. 92, n. 4, p. 791-808, 1998.

HTUN, M. Women's political participation, representation and leadership in Latin America. Issue Brief, Women's Leadership Conference of the Americas, 1998.

Women and democracy. In: DOMÍNGUEZ, J.; SHIFTER, M. (ed.). Constructing democratic governance in Latin America. $2^{\mathrm{a}}$ ed. Baltimore: Johns Hopkins University Press, 2003.

INGLEHART, R. Culture shift. Princeton: Princeton University Press, 1990.

et al. Gender equality and democracy. Ann Arbor: Institute for Social Research, University of Michigan, 2002.

INGLEHART, R.; NORRIS, P. Rising tide: gender equality and cultural change around the world. Cambridge: Cambridge University Press, 2003.

INSTITUTE FOR DEMOCRACY AND ELECTORAL ASSISTANCE (IDEA). Dominican Republic Global Database for Women. 2003. Disponível em: <http://www.quotaproject.org>. Acesso em 7 de outubro de 2005.

JAQUETTE, J. The women's movement in Latin America: feminism and the transition to democracy. London: Unwin Hyman, 1989. 
KELLY, J.M.; ESPINAL, R.; HARTLYN, J. Diferenças de gênero na República Dominicana....

. Women and democracy: regional differences and contrasting views. Journal of Democracy, v. 12, n. 3, p. 111-125, 2001.

JIMÉNEZ POLANCO, J. La representación política de las mujeres en América Latina. América Latina Hoy, v. 22, p. 69.92, 1999.

KELLY, J. M. Political parties and democracy in Latin America. Trabalho apresentado na Reunião Anual de 2002 da American Political Science Association, 29 de agosto a 1 de setembro de 2002, Boston, MA, 2002.

LORBER, J. Gender inequality: feminist theories and politics. Los Angeles: Roxbury Publishing Company, 2001.

LIPSET, S. M.; SCHNEIDER, W. The confidence gap. Ed. ampl. Baltimore: Johns Hopkins University Press, 1987.

MANZA, J. The gender gap in U.S. presidential elections: when? why? implications?. American Journal of Sociology 103 (5): 1235-1266, 1998.

MISHLER, W.; ROSE, R. Trust, distrust and skepticism: popular evaluations of civil and political institutions in post-communist societies. The Journal of Politics, v. 59, n. 2, p. 418 451, 1997.

NORRIS, P.; INGLEHART, R. Women and democracy: cultural obstacles to equal representation. Journal of Democracy, v. 12, n. 3, p. 126-140, 2001.

PAIEWONSKY, D. Institucionalidad, organización de mujeres y consolidación estratégica. Género y Sociedad, v. 2, n. 2, p. 67-81, 1994.

Participación política de las mujeres dominicanas: apuntes históricos y cuestionamientos actuales. Trabalho apresentado na oficina Participación y Democracia, Porto Príncipe. 1997.

PARTICIPACIÓN CIUDADANA. Cuota femenina y voto preferencial. Santo Domingo: Participación Ciudadana, 2001.

PAYNE, M.; ZOVATTO, D.; FLOREZ, F. C.; ZAVALA, A. A. Democracies in development: politics and reform in Latin America. Washington, DC: Johns Hopkins University Press, 2002. 
2003.

La política importa: democracia y desarrollo en América Latina. Washington, DC: IADB,

PHARR, S. J.; PUTNAM, R.; DALTON, R. J. A quarter century of declining confidence. Journal of Democracy, v. 11, n. 2, p. 5-25, 2000.

PUTNAM, R. Tuning in, tuning out: the strange disappearance of social capital in America.

Political Science and Politics, v. 28, n. 4, p. 664-683, 1995a.

Bowling alone: America's declining social capital. Journal of Democracy, v. 5, n. 1, p. $65 \cdot 78,1995 b$.

Bowling alone: the collapse and revival of american community. Nova York: Simon \&

Schuster, 2000.

RENZETTI, C.; CURRAN, D. Women, men and society. Boston: Allyn Bacon, 2003.

SAFA, H. Export manufacturing, state policy, and women workers in the Dominican Republic. In: BONACICH, E. et al. Global production: the apparel industry in the Pacific Rim. Philadelphia:

Temple University Press, 1994.

De mantenidas a proveedoras: mujeres e industrialización en el Caribe. San Juan:

Universidad de Puerto Rico, 1998.

SAINSBURY, D. (ed.). Gender and welfare regimes. Oxford: Oxford University Press, 1999.

SMITH, D. A sociology of women. In: SHERMAN, J.; BECK, E. (ed.). The prism of sex. Madison: University of Wisconsin Press, 1979.

VÁSQUEZ, S. Participación política de las mujeres dominicanas: una reflexión crítica. Género y Sociedad, v. 3, n. 2, p. 122-160, 1995.

ZAITER, J. Mujer y construcción de la identidad social. Género y Sociedad, v. 1, n. 1, p. 85 . 108, 1993.

Recebido para publicação em março de 2006. Aprovado para publicação em julho de 2006.

Tradução de Pedro Maia Soares. 